\title{
SESIUM KLORIDA (CsCl) : TRANSPORT ION DALAM LARUTAN
}

\author{
Amalia Firdaus $^{* 1}$ Rahadian Zainul ${ }^{* 2}$ \\ ${ }^{1}$ Chemistry Education, FMIPA, Universitas Negeri Padang, Indonesia \\ ${ }^{2}$ Physical Chemistry Laboratory, FMIPA, Universitas Negeri Padang, Indonesia \\ ${ }^{1}$ Email: amaliafirdaus40@gmail.com \\ ${ }^{2}$ E-mail : rahadianzmsiphd@yahoo.com
}

\begin{abstract}
Abstrak Sesium klorida adalah senyawa anorganik dengan rumus $\mathrm{CsCl}$. Senyawa ini dapat dengan mudah larut dalam air. Sesium klorida memiliki toksisitas rendah terhadap manusia dan hewan, sedangkan bentuk radioaktif dari senyawa ini dapat dengan mudah mencemari lingkungan karena kelarutan airnya. Senyawa ini digunakan dalam proses sentrifugasi isopicnik dalam pemisahan berbagai jenis DNA dan juga digunakan untuk analisis reagen kimia. Dalam bentuk isotop radio, senyawa ini berguna untuk pengobatan nuklir, yaitu untuk pengobatan kanker. Penelitian ini bertujuan untuk menganalisis interaksi molekuler dan kinetik dari senyawa sesium klorida. Metode yang digunakan adalah dengan pemodelan menggunakan chemoffice serta melalui jurnal hasil penelitian yang berkaitan dengan sesium klorida. Sifat sifat trermokimia dari senyawa sesium klorida dalam fase liquid $\Delta \mathrm{H}^{\mathrm{o}}:-434.47 \mathrm{KJ} / \mathrm{mol}, \mathrm{s}^{\mathrm{o}}: 101.71 \mathrm{~J} / \mathrm{molK}$ dan $\Delta \mathrm{G}^{\mathrm{o}}:-414.5$ $\mathrm{KJ} / \mathrm{mol}$. Data ini di peroleh dari wikipedia. Parameter transfer elektron adalah kecepatan drift, nomor angkut, mobilitas ion, difusi dan hukum I Fick. Keyword : drift speed, transport number, ion mobility, diffusion and I Fick's law
\end{abstract}

\section{Introduction}

Sesium klorida adalah senyawa anorganik (57) dengan rumus CsCl. Senyawa ini dapat dengan mudah larut dalam air. Sesium klorida memiliki kadar racun yang rendah terhadap manusia dan hewan, sementara bentuk radioaktif $(59 ; 60)$ dari senyawa ini dapat dengan mudah mencemari lingkungan karena sifatnya yang mudah larut dalam air.

Senyawa ini digunakan dalam proses sentrifugasi $(62 ; 63)$ isopiknik dalam pemisahan berbagai macam DNA dan juga digunakan untuk reagen $(65 ; 66)$ kimia analisis. Dalam bentuk radio isotopnya (67) senyawa ini berguna untuk kedokteran nuklir yaitu untuk penanganan kanker.

Sifat sifat trermokimia dari senyawa sesium klorida dalam fase liquid $\Delta \mathrm{H}^{\circ}:-434.47 \mathrm{KJ} / \mathrm{mol}, \mathrm{s}^{\mathrm{o}}$ : $101.71 \mathrm{~J} / \mathrm{molK}$ dan $\Delta \mathrm{G}^{\mathrm{o}}:-414.5 \mathrm{KJ} / \mathrm{mol} . \mathrm{Mr} \mathrm{CsCl}: 168.36 \mathrm{~g} / \mathrm{mol} \mathrm{CsCl}$ memiliki konstanta kisi $4,11 \mathrm{~A}$ Data ini di peroleh dari wikipedia

Berbeda dengan natrium klorida dan kalium klorida, senyawa sesium klorida dapat dengan mudah larut dalam asam klorida terkonsentrasi. Cesium klorida ini juga memiliki kelarutan yang relatif tinggi dalam asam format $\left(1077 \mathrm{~g} / \mathrm{L}\right.$ pada $\left.18^{\circ} \mathrm{C}\right)$ dan juga dalam hidrazin.

Bentuk dari senyawa ini berupa kisi kristal sederhana yang mana atom $\mathrm{Cs}^{+}$dikelilingi oleh 8 atom $\mathrm{Cl}^{-}$, begitu pula atom $\mathrm{Cl}^{-}$juga di kelilingi oleh 8 atom $\mathrm{Cs}^{+}$. Sehingga susunan kristal ini membentuk kisi kristal sederhana. Bilangan oksidasi $\mathrm{Cs}$ dan $\mathrm{Cl}$ dalam $\mathrm{CsCl}$ adalah 8.

Dalam tabel periodik unsur, yang umumnya membentuk ikatan ionik adalah unsur pada golongan alkali dan alkali tanah dengan unsur unsur dari golonganhalogen. Namun ada pengecualian pada atom Cs yang mana atom ini memiliki keelektronegativan terendah sehingga ikatan ionik yang terbentukpun tidak sepenuhnya ionik.

Parameter transfer ion berupa kecepatan hanyut, bilangan trasport, mobilitas ion, difusi dan hukum I Fick dari senyawa sesium klorida ini 


\section{Metode}

Metode yang digunakan adalah komputasi dan perhitungan matematika. Proses ini bertujuan untuk mengetahui dan memahami struktur dan karakteristik senyawa $\mathrm{CsCl}$ digunakan data yang diperoleh dari aplikasi Chem Draw profesional 15.0 dan Chem 3D dan juga melalui data jurnal penelitian. Proses menganalisis menggunakan chemdraw yaitu dengan menghitung $\mathrm{MM} 2$ dari molekul $\mathrm{CsCl}$ yang terdiri dari MM2 minimization, MM2 dynamics dan MM2 properties.

Sifat fisika dan kimia dari senyawa ini di dapat dari wikipedia. $\mathrm{CsCl}$ berupa padatan berwarna putih dan larut dalam air serta larut dalam etanol. Massa molar $\quad: 168.36 \mathrm{~g} / \mathrm{mol}$ Penampilan: padat putih Densitas : $3.988 \mathrm{~g} / \mathrm{cm}^{3}$ Titik didih: $1 ; 297^{\circ} \mathrm{C}\left(2 ; 367{ }^{\circ} \mathrm{F} ; 1 ; 570 \mathrm{~K}\right)$ Kelarutan dalam air: $1910 \mathrm{~g} / \mathrm{L}$ $\left(25^{\circ} \mathrm{C}\right)$

Cesium klorida terjadi secara alami sebagai pengotor dalam mineral halida karnalit. Pada skala industri, $\mathrm{CsCl}$ diproduksi dari mineral pollucite, yang bubuk dan direaksikan dengan asam hidroklorida pada suhu tinggi. Ekstrak ini direaksikan lagi dengan antimon klorida, yodium monoklorida, atau cerium (IV) klorida untuk memberikan garam ganda yang kelarutannya buruk.

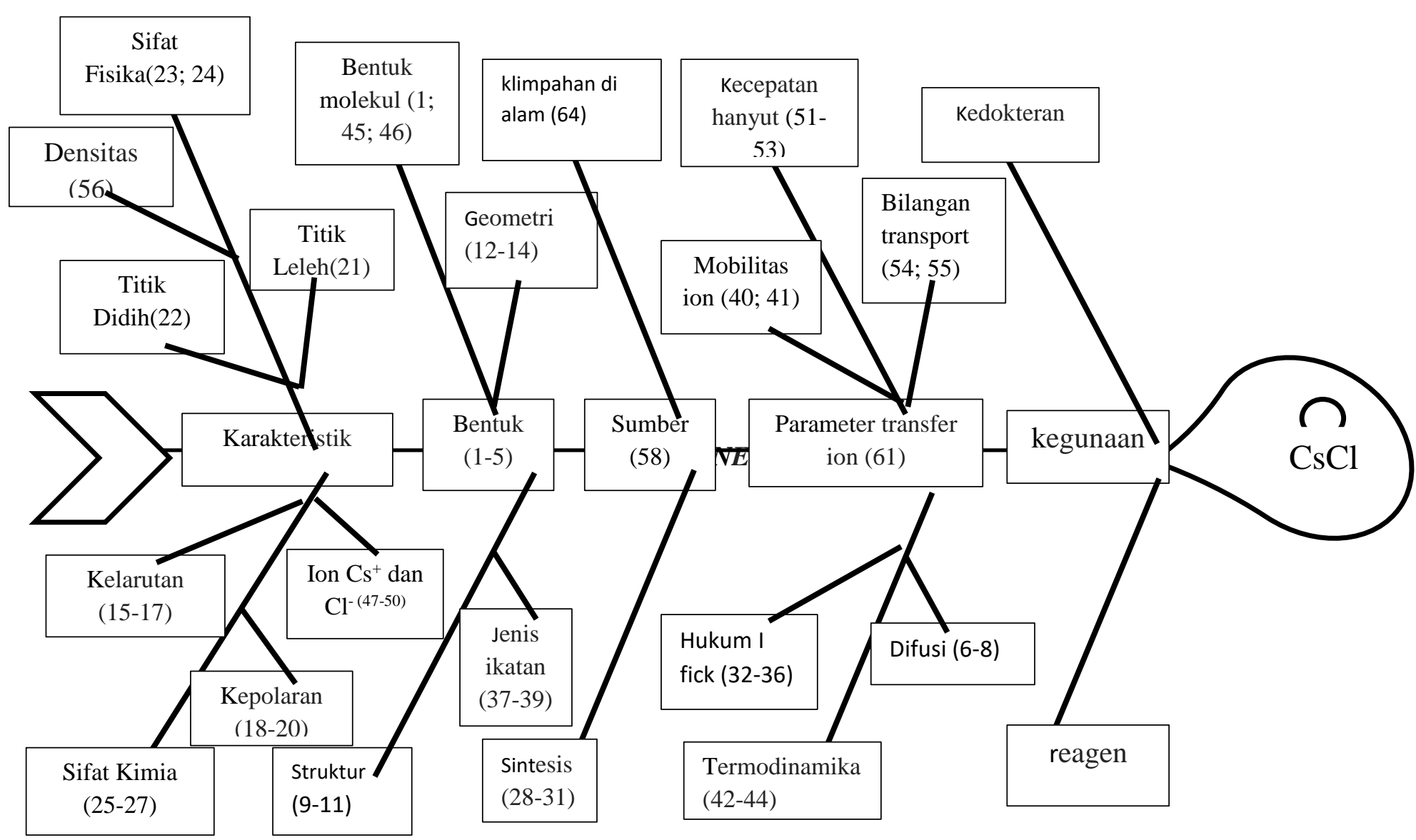




\section{Hasil dan Pembahasan}

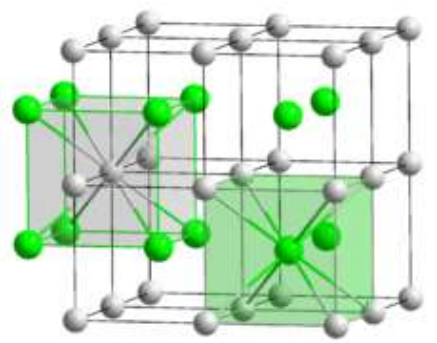

gambar 1 . Secium clorida dalam bentuk kristal sumber 1. https://id.wikipedia.org/wiki/Sesium_klorida

\section{Karakteristik Senyawa Sesium Clorida}

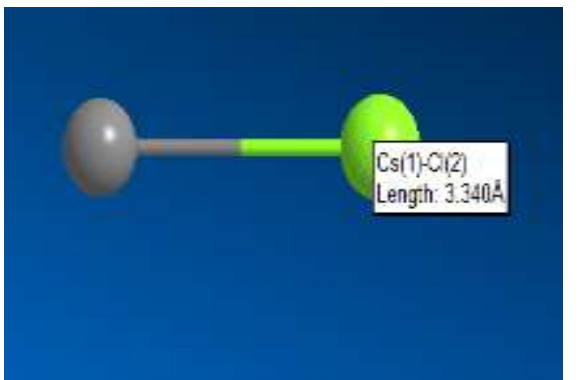

Gambar 2. Pemodelan CsCl

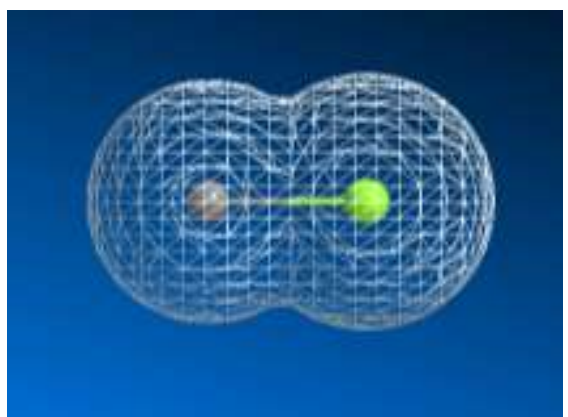

Gambar 4. Struktur dengan Wire maash

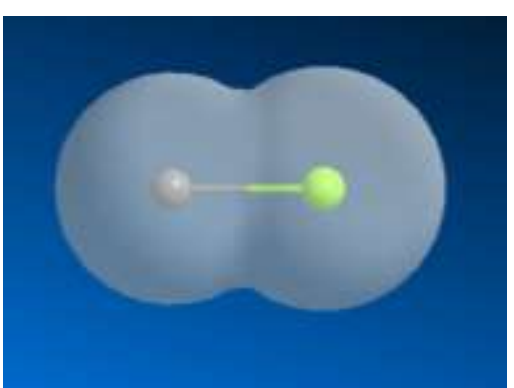

Gambar 3. Struktur dengan permukaan translucent
Rumus kimia

Massa molar

Penampilan

Densitas

Titik didih

Kelarutan dalam air

Struktur kristal

Geometri koordinasi

Jenis ikatan $(68 ; 69)$

$\Delta \mathrm{H}^{\mathrm{o}}(70 ; 71)$

$\mathrm{s}^{\mathrm{o}}(72-74)$

$\Delta \mathrm{G}^{\mathrm{o}}(75 ; 76)$
: $\mathrm{CsCl}$

: $168.36 \mathrm{~g} / \mathrm{mol}$

: padat putih

: $3.988 \mathrm{~g} / \mathrm{cm}^{3}$

: $1 ; 297^{\circ} \mathrm{C}\left(2 ; 367^{\circ} \mathrm{F} ; 1 ; 570 \mathrm{~K}\right)$

$1910 \mathrm{~g} / \mathrm{L}\left(25^{\circ} \mathrm{C}\right)$

$\mathrm{CsCl}, \mathrm{cP} 2$

Kubik $\left(\mathrm{Cs}^{+}\right)$

Kubik $\left(\mathrm{Cl}^{-}\right)$

: ikatan ion

: $-434.47 \mathrm{KJ} / \mathrm{mol}$

: $101.71 \mathrm{~J} / \mathrm{molK}$

: $-414.5 \mathrm{KJ} / \mathrm{mol} \Delta \mathrm{G}^{\mathrm{o}}$ : $-414.5 \mathrm{KJ} / \mathrm{mol}$ 
1. Optimasi MM2

MM2 Calculation completed successfully

-MM2 Minimization-

Warning: The number of ligands attached does not match the geometry of $\operatorname{Si}(3)$

Warning: Some parameters are guessed (Quality $=1$ ).

Iteration 1 Steric Energy -122.130 RMS Gradient 23.993 RMS Move 0.0000

Iteration 2 Steric Energy -212.644 RMS Gradient 57.470 RMS Move 0.2041

Iteration 3 Steric Energy -221.997 RMS Gradient 41.854 RMS Move 0.0385

Iteration 4 Steric Energy -233.539 RMS Gradient 18.147 RMS Move 0.0309

Iteration 5 Steric Energy -236.236 RMS Gradient 12.682 RMS Move 0.0149

Iteration 6 Steric Energy -237.883 RMS Gradient 9.204 RMS Move 0.0099

Iteration 7 Steric Energy -239.990 RMS Gradient 12.894 RMS Move 0.0276

Iteration 8 Steric Energy -241.259 RMS Gradient 11.827 RMS Move 0.0151

Iteration 9 Steric Energy -245.166 RMS Gradient 7.373 RMS Move 0.0433

Iteration 10 Steric Energy -249.577 RMS Gradient 20.063 RMS Move 0.0883

Iteration 11 Steric Energy -252.310 RMS Gradient 13.393 RMS Move 0.0408

Iteration 12 Steric Energy -254.918 RMS Gradient 14.926 RMS Move 0.0590

Iteration 13 Steric Energy -256.360 RMS Gradient 11.614 RMS Move 0.0171

Iteration 14 Steric Energy -259.908 RMS Gradient 9.477 RMS Move 0.0434

Iteration 15 Steric Energy -261.062 RMS Gradient 12.019 RMS Move 0.0199

Iteration 16 Steric Energy -263.318 RMS Gradient 12.278 RMS Move 0.0530

Iteration 17 Steric Energy -264.950 RMS Gradient 10.294 RMS Move 0.0215

Iteration 18 Steric Energy -267.166 RMS Gradient 16.546 RMS Move 0.0380

Iteration 19 Steric Energy -269.278 RMS Gradient 15.579 RMS Move 0.0449

Iteration 20 Steric Energy -272.384 RMS Gradient 16.636 RMS Move 0.0401

Iteration 21 Steric Energy -274.247 RMS Gradient 11.700 RMS Move 0.0156

Iteration 22 Steric Energy -275.567 RMS Gradient 7.169 RMS Move 0.0089

Iteration 23 Steric Energy -277.247 RMS Gradient 13.699 RMS Move 0.0280

Iteration 24 Steric Energy -279.058 RMS Gradient 21.192 RMS Move 0.0425

Iteration 25 Steric Energy -285.299 RMS Gradient 19.689 RMS Move 0.0695

Iteration 26 Steric Energy -291.627 RMS Gradient 24.747 RMS Move 0.0717

Iteration 27 Steric Energy -293.837 RMS Gradient 16.321 RMS Move 0.0395

Iteration 28 Steric Energy -295.347 RMS Gradient 8.694 RMS Move 0.0063

Iteration 29 Steric Energy -296.119 RMS Gradient 8.327 RMS Move 0.0077

Iteration 30 Steric Energy -296.667 RMS Gradient 4.592 RMS Move 0.0050

Iteration 31 Steric Energy -297.380 RMS Gradient 6.134 RMS Move 0.0178

Iteration 32 Steric Energy -297.619 RMS Gradient 6.410 RMS Move 0.0093

Iteration 33 Steric Energy -297.785 RMS Gradient 4.072 RMS Move 0.0032

Iteration 34 Steric Energy -297.896 RMS Gradient 2.270 RMS Move 0.0019

Iteration 35 Steric Energy -298.214 RMS Gradient 2.323 RMS Move 0.0106

Iteration 36 Steric Energy -298.358 RMS Gradient 4.346 RMS Move 0.0081

Iteration 37 Steric Energy -298.614 RMS Gradient 4.877 RMS Move 0.0173

Iteration 38 Steric Energy -298.802 RMS Gradient 2.945 RMS Move 0.0072

Iteration 39 Steric Energy -298.933 RMS Gradient 2.894 RMS Move 0.0045

Iteration 40 Steric Energy -299.307 RMS Gradient 2.453 RMS Move 0.0175

Iteration 41 Steric Energy -299.405 RMS Gradient 2.784 RMS Move 0.0082

Iteration 42 Steric Energy -299.478 RMS Gradient 1.709 RMS Move 0.0052

Iteration 43 Steric Energy -299.616 RMS Gradient 3.021 RMS Move 0.0177

Iteration 44 Steric Energy -299.855 RMS Gradient 3.926 RMS Move 0.0305

Iteration 45 Steric Energy -299.945 RMS Gradient 3.145 RMS Move 0.0150

Iteration 46 Steric Energy -300.055 RMS Gradient 3.246 RMS Move 0.0169

Iteration 47 Steric Energy -300.112 RMS Gradient 2.625 RMS Move 0.0036

Iteration 48 Steric Energy -300.214 RMS Gradient 2.222 RMS Move 0.0067 
Iteration 49 Steric Energy -300.270 RMS Gradient 2.133 RMS Move 0.0039 Iteration 50 Steric Energy -300.305 RMS Gradient 1.099 RMS Move 0.0019

$\begin{array}{ll}\text { Stretch } & : 0.4136 \\ \text { Bend } & : 6.9206 \\ \text { Stretch-Bend } & :-0.6266 \\ \text { Torsion } & : 19.8219 \\ \text { Non-1,4 VDW } & : 61.4635 \\ \text { 1,4 VDW } & : 1.0594 \\ \text { Charge/Charge } & :-424.9349 \\ \text { Charge/Dipole } & :-15.6811 \\ \text { Total Energy } & :-351.5636 \mathrm{kcal} / \mathrm{mol}\end{array}$

Note: Due to high VDW interactions, some terms were not computed.

Calculation ended

MM2 Calculation completed successfully -MM2 Dynamics-

Warning: The number of ligands attached does not match the geometry of $\operatorname{Si}(3)$

Warning: Some parameters are guessed (Quality $=1$ ).

Iteration Time Total Energy Potential Energy Temperature

$\begin{array}{cccccc}1 & 0.002 & -351.564 \pm 0.000 & -351.564 \pm 0.000 & 0.00 \pm 0.00 \\ 2 & 0.004 & -351.551 \pm 0.000 & -351.557 \pm 0.000 & 0.26 \pm 0.00 \\ 3 & 0.006 & -351.539 \pm 0.000 & -351.551 \pm 0.000 & 0.52 \pm 0.00 \\ 4 & 0.008 & -351.518 \pm 0.000 & -351.552 \pm 0.000 & 1.44 \pm 0.00 \\ 5 & 0.010 & -351.516 \pm 0.000 & -351.553 \pm 0.000 & 1.56 \pm 0.00 \\ 6 & 0.012 & -351.508 \pm 0.000 & -351.555 \pm 0.000 & 1.96 \pm 0.00 \\ 7 & 0.014 & -351.488 \pm 0.000 & -351.544 \pm 0.000 & 2.31 \pm 0.00 \\ 8 & 0.016 & -351.484 \pm 0.000 & -351.541 \pm 0.000 & 2.39 \pm 0.00 \\ 9 & 0.018 & -351.441 \pm 0.000 & -351.497 \pm 0.000 & 2.35 \pm 0.00 \\ 10 & 0.020 & -351.421 \pm 0.000 & -351.489 \pm 0.000 & 2.86 \pm 0.00 \\ 11 & 0.022 & -351.402 \pm 0.000 & -351.525 \pm 0.000 & 5.14 \pm 0.00 \\ 12 & 0.024 & -351.387 \pm 0.000 & -351.475 \pm 0.000 & 3.67 \pm 0.00 \\ 13 & 0.026 & -351.381 \pm 0.000 & -351.516 \pm 0.000 & 5.69 \pm 0.00 \\ 14 & 0.028 & -351.366 \pm 0.000 & -351.504 \pm 0.000 & 5.80 \pm 0.00 \\ 15 & 0.030 & -351.358 \pm 0.000 & -351.457 \pm 0.000 & 4.15 \pm 0.00 \\ 16 & 0.032 & -351.353 \pm 0.000 & -351.506 \pm 0.000 & 6.43 \pm 0.00 \\ 17 & 0.034 & -351.327 \pm 0.000 & -351.469 \pm 0.000 & 5.92 \pm 0.00 \\ 18 & 0.036 & -351.328 \pm 0.000 & -351.459 \pm 0.000 & 5.48 \pm 0.00 \\ 19 & 0.038 & -351.320 \pm 0.000 & -351.489 \pm 0.000 & 7.08 \pm 0.00 \\ 20 & 0.040 & -351.318 \pm 0.000 & -351.431 \pm 0.000 & 4.74 \pm 0.00 \\ 21 & 0.042 & -351.323 \pm 0.000 & -351.450 \pm 0.000 & 5.34 \pm 0.00 \\ 22 & 0.044 & -351.304 \pm 0.000 & -351.446 \pm 0.000 & 5.94 \pm 0.00 \\ 23 & 0.046 & -351.305 \pm 0.000 & -351.392 \pm 0.000 & 3.65 \pm 0.00 \\ 24 & 0.048 & -351.295 \pm 0.000 & -351.442 \pm 0.000 & 6.14 \pm 0.00 \\ 25 & 0.050 & -351.249 \pm 0.000 & -351.417 \pm 0.000 & 7.03 \pm 0.00 \\ 26 & 0.052 & -351.261 \pm 0.000 & -351.420 \pm 0.000 & 6.65 \pm 0.00 \\ 27 & 0.054 & -351.245 \pm 0.000 & -351.464 \pm 0.000 & 9.18 \pm 0.00 \\ 28 & 0.056 & -351.225 \pm 0.000 & -351.381 \pm 0.000 & 6.51 \pm 0.00 \\ 29 & 0.058 & -351.226 \pm 0.000 & -351.438 \pm 0.000 & 8.88 \pm 0.00 \\ 30 & 0.060 & -351.214 \pm 0.000 & -351.468 \pm 0.000 & 10.67 \pm 0.00 \\ 31 & 0.062 & -351.219 \pm 0.000 & -351.415 \pm 0.000 & 8.20 \pm 0.00\end{array}$




$\begin{array}{llllll}32 & 0.064 & -351.215 \pm 0.000 & -351.445 \pm 0.000 & 9.66 \pm 0.00 \\ 33 & 0.066 & -351.202 \pm 0.000 & -351.425 \pm 0.000 & 9.35 \pm 0.00 \\ 34 & 0.068 & -351.189 \pm 0.000 & -351.397 \pm 0.000 & 8.75 \pm 0.00 \\ 35 & 0.070 & -351.168 \pm 0.000 & -351.426 \pm 0.000 & 10.83 \pm 0.00 \\ 36 & 0.072 & -351.164 \pm 0.000 & -351.368 \pm 0.000 & 8.55 \pm 0.00 \\ 37 & 0.074 & -351.156 \pm 0.000 & -351.366 \pm 0.000 & 8.82 \pm 0.00 \\ 38 & 0.076 & -351.152 \pm 0.000 & -351.424 \pm 0.000 & 11.42 \pm 0.00 \\ 39 & 0.078 & -351.139 \pm 0.000 & -351.404 \pm 0.000 & 11.12 \pm 0.00 \\ 40 & 0.080 & -351.138 \pm 0.000 & -351.435 \pm 0.000 & 12.44 \pm 0.00 \\ 41 & 0.082 & -351.120 \pm 0.000 & -351.412 \pm 0.000 & 12.24 \pm 0.00 \\ 42 & 0.084 & -351.117 \pm 0.000 & -351.382 \pm 0.000 & 11.14 \pm 0.00 \\ 43 & 0.086 & -351.109 \pm 0.000 & -351.444 \pm 0.000 & 14.08 \pm 0.00 \\ 44 & 0.088 & -351.087 \pm 0.000 & -351.404 \pm 0.000 & 13.31 \pm 0.00 \\ 45 & 0.090 & -351.076 \pm 0.000 & -351.359 \pm 0.000 & 11.87 \pm 0.00 \\ 46 & 0.092 & -351.066 \pm 0.000 & -351.361 \pm 0.000 & 12.38 \pm 0.00 \\ 47 & 0.094 & -351.055 \pm 0.000 & -351.299 \pm 0.000 & 10.20 \pm 0.00 \\ 48 & 0.096 & -351.043 \pm 0.000 & -351.314 \pm 0.000 & 11.35 \pm 0.00 \\ 49 & 0.098 & -351.029 \pm 0.000 & -351.288 \pm 0.000 & 10.88 \pm 0.00 \\ 50 & 0.100 & -351.011 \pm 0.000 & -351.210 \pm 0.000 & 8.36 \pm 0.00\end{array}$

MM2 Calculation completed successfully -MM2 Minimization-

Warning: The number of ligands attached does not match the geometry of $\operatorname{Cs}(1)$ Warning: The number of ligands attached does not match the geometry of $\mathrm{Cl}(2)$ Warning: Some parameters are guessed (Quality $=1$ ).

Iteration 1 Steric Energy 0.000 RMS Gradient 0.000 RMS Move 0.0000

Iteration 2 Steric Energy 0.000 RMS Gradient 0.000 RMS Move 0.0000

Iteration 2: Minimization terminated normally because the gradient norm is less than the minimum

$\begin{array}{lc} & \text { gradient norm } \\ \text { Stretch } & : 0.0000 \\ \text { Bend } & : 0.0000 \\ \text { Stretch-Bend } & : 0.0000 \\ \text { Torsion } & : 0.0000 \\ \text { Non-1,4 VDW } & : 0.0000 \\ \text { 1,4 VDW } & : 0.0000 \\ \text { Charge/Charge } & : 0.0000 \\ \text { Total Energy: } & 0.0000 \mathrm{kcal} / \mathrm{mol} \\ \text { Calculation ended } & \end{array}$

2. Optimasi

MM2 Calculation completed successfully -MM2 Minimization-

Warning: The number of ligands attached does not match the geometry of $\operatorname{Si}(3)$

Warning: Some parameters are guessed (Quality $=1$ ).

Iteration 1 Steric Energy -122.130 RMS Gradient 23.993 RMS Move 0.0000

Iteration 2 Steric Energy -212.644 RMS Gradient 57.470 RMS Move 0.2041

Iteration 3 Steric Energy -221.997 RMS Gradient 41.854 RMS Move 0.0385

Iteration 4 Steric Energy -233.539 RMS Gradient 18.147 RMS Move 0.0309

Iteration 5 Steric Energy -236.236 RMS Gradient 12.682 RMS Move 0.0149

Iteration 6 Steric Energy -237.883 RMS Gradient 9.204 RMS Move 0.0099

Iteration 7 Steric Energy -239.990 RMS Gradient 12.894 RMS Move 0.0276

Iteration 8 Steric Energy -241.259 RMS Gradient 11.827 RMS Move 0.0151

Iteration 9 Steric Energy -245.166 RMS Gradient 7.373 RMS Move 0.0433 
Iteration 10 Steric Energy -249.577 RMS Gradient 20.063 RMS Move 0.0883

Iteration 11 Steric Energy -252.310 RMS Gradient 13.393 RMS Move 0.0408

Iteration 12 Steric Energy -254.918 RMS Gradient 14.926 RMS Move 0.0590

Iteration 13 Steric Energy -256.360 RMS Gradient 11.614 RMS Move 0.0171

Iteration 14 Steric Energy -259.908 RMS Gradient 9.477 RMS Move 0.0434

Iteration 15 Steric Energy -261.062 RMS Gradient 12.019 RMS Move 0.0199

Iteration 16 Steric Energy -263.318 RMS Gradient 12.278 RMS Move 0.0530

Iteration 17 Steric Energy -264.950 RMS Gradient 10.294 RMS Move 0.0215

Iteration 18 Steric Energy -267.166 RMS Gradient 16.546 RMS Move 0.0380

Iteration 19 Steric Energy -269.278 RMS Gradient 15.579 RMS Move 0.0449

Iteration 20 Steric Energy -272.384 RMS Gradient 16.636 RMS Move 0.0401

Iteration 21 Steric Energy -274.247 RMS Gradient 11.700 RMS Move 0.0156

Iteration 22 Steric Energy -275.567 RMS Gradient 7.169 RMS Move 0.0089

Iteration 23 Steric Energy -277.247 RMS Gradient 13.699 RMS Move 0.0280

Iteration 24 Steric Energy -279.058 RMS Gradient 21.192 RMS Move 0.0425

Iteration 25 Steric Energy -285.299 RMS Gradient 19.689 RMS Move 0.0695

Iteration 26 Steric Energy -291.627 RMS Gradient 24.747 RMS Move 0.0717

Iteration 27 Steric Energy -293.837 RMS Gradient 16.321 RMS Move 0.0395

Iteration 28 Steric Energy -295.347 RMS Gradient 8.694 RMS Move 0.0063

Iteration 29 Steric Energy -296.119 RMS Gradient 8.327 RMS Move 0.0077

Iteration 30 Steric Energy -296.667 RMS Gradient 4.592 RMS Move 0.0050

Iteration 31 Steric Energy -297.380 RMS Gradient 6.134 RMS Move 0.0178

Iteration 32 Steric Energy -297.619 RMS Gradient 6.410 RMS Move 0.0093

Iteration 33 Steric Energy -297.785 RMS Gradient 4.072 RMS Move 0.0032

Iteration 34 Steric Energy -297.896 RMS Gradient 2.270 RMS Move 0.0019

Iteration 35 Steric Energy -298.214 RMS Gradient 2.323 RMS Move 0.0106

Iteration 36 Steric Energy -298.358 RMS Gradient 4.346 RMS Move 0.0081

Iteration 37 Steric Energy -298.614 RMS Gradient 4.877 RMS Move 0.0173

Iteration 38 Steric Energy -298.802 RMS Gradient 2.945 RMS Move 0.0072

Iteration 39 Steric Energy -298.933 RMS Gradient 2.894 RMS Move 0.0045

Iteration 40 Steric Energy -299.307 RMS Gradient 2.453 RMS Move 0.0175

Iteration 41 Steric Energy -299.405 RMS Gradient 2.784 RMS Move 0.0082

Iteration 42 Steric Energy -299.478 RMS Gradient 1.709 RMS Move 0.0052

Iteration 43 Steric Energy -299.616 RMS Gradient 3.021 RMS Move 0.0177

Iteration 44 Steric Energy -299.855 RMS Gradient 3.926 RMS Move 0.0305

Iteration 45 Steric Energy -299.945 RMS Gradient 3.145 RMS Move 0.0150

Iteration 46 Steric Energy -300.055 RMS Gradient 3.246 RMS Move 0.0169

Iteration 47 Steric Energy -300.112 RMS Gradient 2.625 RMS Move 0.0036

Iteration 48 Steric Energy -300.214 RMS Gradient 2.222 RMS Move 0.0067

Iteration 49 Steric Energy -300.270 RMS Gradient 2.133 RMS Move 0.0039

Iteration 50 Steric Energy -300.305 RMS Gradient 1.099 RMS Move 0.0019

$\begin{array}{ll}\text { Stretch } & : 0.4136 \\ \text { Bend } & : 6.9206 \\ \text { Stretch-Bend } & :-0.6266 \\ \text { Torsion } & : 19.8219 \\ \text { Non-1,4 VDW } & : 61.4635 \\ 1,4 \text { VDW } & : 1.0594 \\ \text { Charge/Charge } & :-424.9349 \\ \text { Charge/Dipole } & :-15.6811 \\ \text { Total Energy } & :-351.5636 \mathrm{kcal} / \mathrm{mol}\end{array}$

Note: Due to high VDW interactions, some terms were not computed.

Calculation ended 
MM2 Calculation completed successfully -MM2 Dynamics

Warning: The number of ligands attached does not match the geometry of $\operatorname{Si}(3)$

Warning: Some parameters are guessed (Quality $=1$ ).

Iteration Time Total Energy Potential Energy Temperature

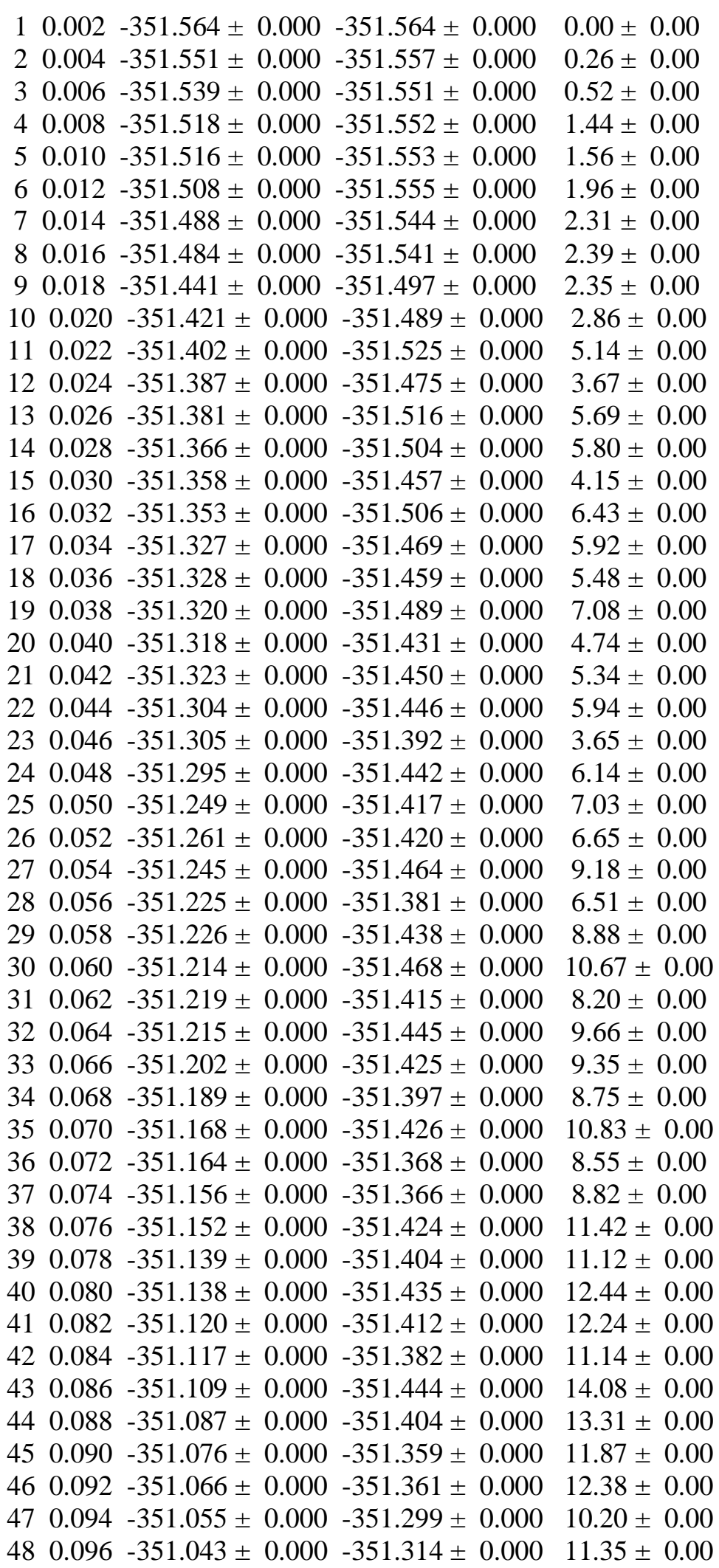


$490.098-351.029 \pm 0.000-351.288 \pm 0.000 \quad 10.88 \pm 0.00$

$50 \quad 0.100-351.011 \pm 0.000-351.210 \pm 0.000 \quad 8.36 \pm 0.00$

MM2 Calculation completed successfully

-MM2 Minimization

Warning: The number of ligands attached does not match the geometry of Cs(1)

Warning: The number of ligands attached does not match the geometry of $\mathrm{Cl}(2)$

Warning: Some parameters are guessed (Quality $=1$ ).

Iteration 1 Steric Energy 0.000 RMS Gradient 0.000 RMS Move 0.0000

Iteration 2 Steric Energy 0.000 RMS Gradient 0.000 RMS Move 0.0000

Iteration 2: Minimization terminated normally because the gradient norm is less than the minimum

Stretch $\quad: 0.0000$

Bend $\quad: 0.0000$

Stretch-Bend $\quad: 0.0000$

Torsion $\quad: 0.0000$

Non-1,4 VDW $\quad: 0.0000$

$1,4 \mathrm{VDW} \quad: 0.0000$

Charge/Charge $\quad: 0.0000$

Total Energy $\quad: 0.0000 \mathrm{kcal} / \mathrm{mol}$

Calculation ended

MM2 Calculation completed successfully

-MM2 Dynamics

Warning: The number of ligands attached does not match the geometry of Cs(1)

Warning: The number of ligands attached does not match the geometry of $\mathrm{Cl}(2)$

Warning: Some parameters are guessed (Quality $=1$ ).

Iteration Time Total Energy Potential Energy Temperature

$\begin{array}{ccccc}1 & 0.002 & 0.000 \pm 0.000 & 0.000 \pm 0.000 & 0.00 \pm 0.00 \\ 2 & 0.004 & 0.009 \pm 0.000 & 0.001 \pm 0.000 & 1.32 \pm 0.00 \\ 3 & 0.006 & 0.012 \pm 0.000 & 0.005 \pm 0.000 & 1.25 \pm 0.00 \\ 4 & 0.008 & 0.023 \pm 0.000 & 0.013 \pm 0.000 & 1.79 \pm 0.00 \\ 5 & 0.010 & 0.029 \pm 0.000 & 0.022 \pm 0.000 & 1.04 \pm 0.00 \\ 6 & 0.012 & 0.040 \pm 0.000 & 0.035 \pm 0.000 & 0.84 \pm 0.00 \\ 7 & 0.014 & 0.043 \pm 0.000 & 0.042 \pm 0.000 & 0.06 \pm 0.00 \\ 8 & 0.016 & 0.047 \pm 0.000 & 0.047 \pm 0.000 & 0.01 \pm 0.00 \\ 9 & 0.018 & 0.055 \pm 0.000 & 0.029 \pm 0.000 & 4.29 \pm 0.00 \\ 10 & 0.020 & 0.063 \pm 0.000 & 0.009 \pm 0.000 & 8.98 \pm 0.00 \\ 11 & 0.022 & 0.065 \pm 0.000 & 0.000 \pm 0.000 & 10.91 \pm 0.00 \\ 12 & 0.024 & 0.073 \pm 0.000 & 0.008 \pm 0.000 & 10.89 \pm 0.00 \\ 13 & 0.026 & 0.084 \pm 0.000 & 0.034 \pm 0.000 & 8.42 \pm 0.00 \\ 14 & 0.028 & 0.086 \pm 0.000 & 0.064 \pm 0.000 & 3.62 \pm 0.00 \\ 15 & 0.030 & 0.088 \pm 0.000 & 0.085 \pm 0.000 & 0.44 \pm 0.00 \\ 16 & 0.032 & 0.095 \pm 0.000 & 0.095 \pm 0.000 & 0.02 \pm 0.00 \\ 17 & 0.034 & 0.098 \pm 0.000 & 0.072 \pm 0.000 & 4.36 \pm 0.00 \\ 18 & 0.036 & 0.100 \pm 0.000 & 0.036 \pm 0.000 & 10.86 \pm 0.00 \\ 19 & 0.038 & 0.109 \pm 0.000 & 0.006 \pm 0.000 & 17.18 \pm 0.00 \\ 20 & 0.040 & 0.125 \pm 0.000 & 0.002 \pm 0.000 & 20.60 \pm 0.00 \\ 21 & 0.042 & 0.126 \pm 0.000 & 0.029 \pm 0.000 & 16.37 \pm 0.00 \\ 22 & 0.044 & 0.136 \pm 0.000 & 0.075 \pm 0.000 & 10.21 \pm 0.00 \\ 23 & 0.046 & 0.138 \pm 0.000 & 0.118 \pm 0.000 & 3.31 \pm 0.00 \\ 24 & 0.048 & 0.138 \pm 0.000 & 0.137 \pm 0.000 & 0.03 \pm 0.00\end{array}$




$\begin{array}{lllll}25 & 0.050 & 0.139 \pm 0.000 & 0.132 \pm 0.000 & 1.20 \pm 0.00 \\ 26 & 0.052 & 0.142 \pm 0.000 & 0.094 \pm 0.000 & 8.06 \pm 0.00 \\ 27 & 0.054 & 0.150 \pm 0.000 & 0.041 \pm 0.000 & 18.24 \pm 0.00 \\ 28 & 0.056 & 0.152 \pm 0.000 & 0.005 \pm 0.000 & 24.67 \pm 0.00 \\ 29 & 0.058 & 0.154 \pm 0.000 & 0.005 \pm 0.000 & 24.99 \pm 0.00 \\ 30 & 0.060 & 0.157 \pm 0.000 & 0.042 \pm 0.000 & 19.41 \pm 0.00 \\ 31 & 0.062 & 0.170 \pm 0.000 & 0.102 \pm 0.000 & 11.38 \pm 0.00 \\ 32 & 0.064 & 0.178 \pm 0.000 & 0.158 \pm 0.000 & 3.43 \pm 0.00 \\ 33 & 0.066 & 0.185 \pm 0.000 & 0.185 \pm 0.000 & 0.02 \pm 0.00 \\ 34 & 0.068 & 0.186 \pm 0.000 & 0.172 \pm 0.000 & 2.36 \pm 0.00 \\ 35 & 0.070 & 0.195 \pm 0.000 & 0.110 \pm 0.000 & 14.25 \pm 0.00 \\ 36 & 0.072 & 0.199 \pm 0.000 & 0.040 \pm 0.000 & 26.65 \pm 0.00 \\ 37 & 0.074 & 0.210 \pm 0.000 & 0.002 \pm 0.000 & 34.96 \pm 0.00 \\ 38 & 0.076 & 0.222 \pm 0.000 & 0.017 \pm 0.000 & 34.43 \pm 0.00 \\ 39 & 0.078 & 0.223 \pm 0.000 & 0.078 \pm 0.000 & 24.22 \pm 0.00 \\ 40 & 0.080 & 0.230 \pm 0.000 & 0.158 \pm 0.000 & 12.04 \pm 0.00 \\ 41 & 0.082 & 0.232 \pm 0.000 & 0.218 \pm 0.000 & 2.34 \pm 0.00 \\ 42 & 0.084 & 0.232 \pm 0.000 & 0.230 \pm 0.000 & 0.34 \pm 0.00 \\ 43 & 0.086 & 0.235 \pm 0.000 & 0.182 \pm 0.000 & 8.94 \pm 0.00 \\ 44 & 0.088 & 0.237 \pm 0.000 & 0.101 \pm 0.000 & 22.84 \pm 0.00 \\ 45 & 0.090 & 0.244 \pm 0.000 & 0.027 \pm 0.000 & 36.42 \pm 0.00 \\ 46 & 0.092 & 0.248 \pm 0.000 & 0.000 \pm 0.000 & 41.57 \pm 0.00 \\ 47 & 0.094 & 0.267 \pm 0.000 & 0.039 \pm 0.000 & 38.36 \pm 0.00 \\ 48 & 0.096 & 0.282 \pm 0.000 & 0.130 \pm 0.000 & 25.39 \pm 0.00 \\ 49 & 0.098 & 0.292 \pm 0.000 & 0.233 \pm 0.000 & 9.99 \pm 0.00 \\ 50 & 0.100 & 0.295 \pm 0.000 & 0.292 \pm 0.000 & 0.54 \pm 0.00\end{array}$

Translational Kinetic Energy: 0.0000 Rotational Kinetic Energy: 0.0000 Calculation ended

Sesium clorida $(77 ; 78)$ merupakan senyawa anorganik (57) yang berbentuk padat berwarna putih yang dapat larut dalam air dan etanol $(79 ; 80)$. Senyawa ini bersifat higroskopik(81-83) yang berarti mampu menyerap molekul $(84 ; 85)$ air yang ada di sekitarnya atau lingkungan.

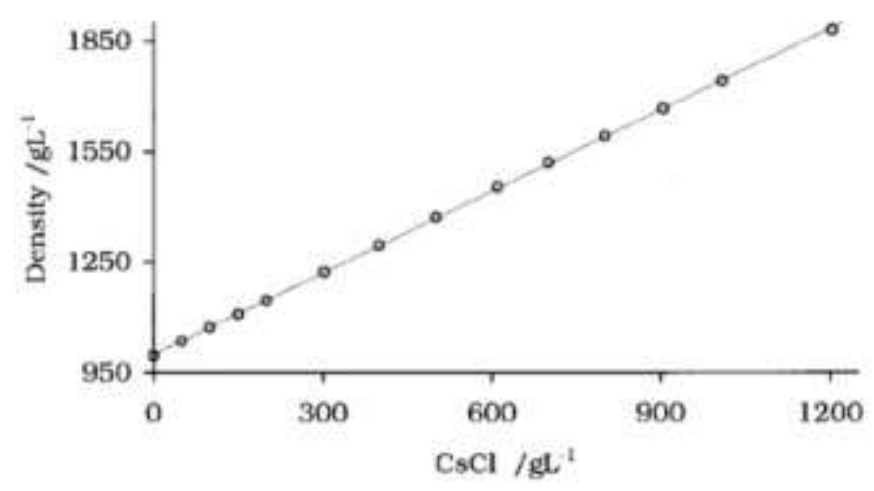

grafik 1. Densitas $\mathrm{CsCl}$ di dalam larutan

sumber 2. https://www.researchgate.net/figure/Density-of-CsCl-aqueous-solutions-as-a-function-of-CsClconcentration_fig1_257993884

\section{Bentuk Molekul Sesium Klorida}

Kristal $(86 ; 87)$ dari senyawa ionik terbentuk karena susunan dari kation dan anion yang terus berulang. Pola penyusunan ion ion ini menghasilkan kisi kristal (88) dalam bentuk tertentu pula. Sesium kloridaa merupakan salah satu contoh dari bentuk kisi kristal tersebut. Sesium klorida merupakan senyawa ionik $(89 ; 90)$ yang terdiri dari ion $\mathrm{CS}^{+}$dan ion $\mathrm{Cl}^{-}$. 
Kisi kristal sesium klorida ini bukan merupakan bentuk kubus berpusat badan atau Body Center Cubic (BCC) melainkan berbentuk kubus sederhana atau primitif cubic.
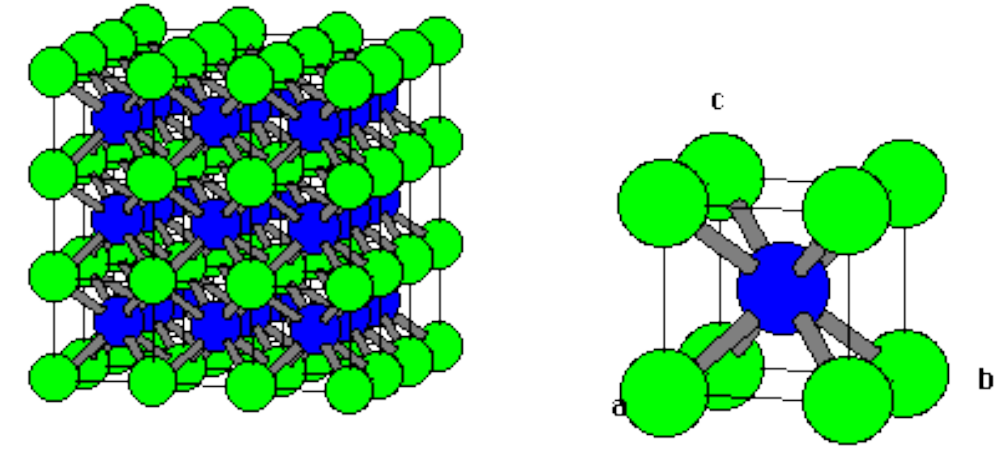

Figure 1. (kiri) bentuk kisi kristal CsCl, (kanan) bentuk sel tunggal CsCl sumber 3. http://www.ilpi.com/inorganic/structures/cscl/index.html

Atom $\mathrm{Cs}^{+}$dikelilingi oleh 8 atom $\mathrm{Cl}^{-}$, begitu pula atom $\mathrm{Cl}^{-}$juga di kelilingi oleh 8 atom $\mathrm{Cs}^{+}$. Sehingga susunan kristal ini membentuk kisi kristal sederhana.

Atom penyusun sesium klorida

$>$ Sesium

Jari-jari atom

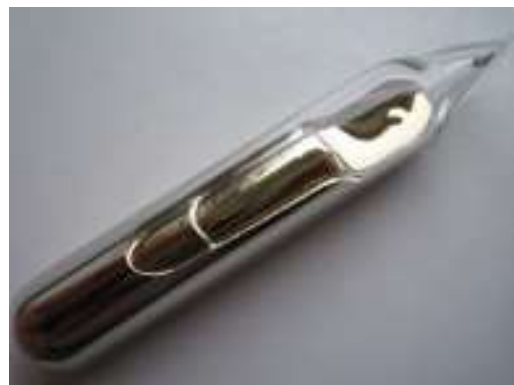

sumber 4. https://en.wikipedia.org/wiki/Caesium gambar 5. Logam Sesium

Jari-jari kovalen : empiris: $265 \mathrm{pm}$

Titik didih

: $244 \pm 11 \mathrm{pm}$

Titik lebur

$$
\text { : } 944 \mathrm{~K}\left(671{ }^{\circ} \mathrm{C}, 1240^{\circ} \mathrm{F}\right)
$$

Sesium (91-94) merupakan logam alkali (47; 95) yang memiliki no atom 55 dan berbentuk cair dalam suhu kamar berwarna putih keemasan. Sesium adalah logam alkali yang terdapat di lepidolite (96), pollucte (silikat aluminum dan Sesium basah) dan di sumber-sumber lainnya. Salah satu tempat yang menjadi sumber terkaya yang mengandung Sesium terdapat di danau Bernic di Manitoba, Kanada. Deposit di danau ini diperkirakan mengandung 300.000 ton pollucite yang mengandung 20\% Sesium. Unsur ini juga dapat diisolasi dengan cara elektrolisis $(97 ; 98)$ fusi sianida dan dengan beberapa metoda lainnya. Kegunaan yang paling terkenal dari senyawa ini adalah jam atom. Jam atom ini digunakan olh ilmuan sebagai referensi untuk memantau waktu tempuh riset dengan sangat tepat.

\section{$>$ Clorida}

Jari-jari atom

Jari-jari kovalen

Titik didih

Titik lebur

$$
\text { : empiris: } \underline{100} \mathrm{pm}
$$$$
\text { : } \underline{99} \mathrm{pm}
$$$$
\text { : } 239,11 \mathrm{~K}\left(-34,4^{\circ} \mathrm{C},-29,27^{\circ} \mathrm{F}\right)
$$

: $171,6 \underline{\mathrm{K}}\left(-101,5^{\circ} \mathrm{C},-150,7^{\circ} \mathrm{F}\right)$ (https://id.wikipedia.org/wiki/Klor)

Ion Klorida $\left(\mathrm{Cl}^{-}\right)$adalah sebuah anion (99-101) yang membentuk bagian yang bermuatan negatif dari garam tertentu, termasuk garam natrium $(102 ; 103)$ dan hidrogen klorida, dan juga 
merupakan elektrolit (104) penting yang terletak di semua cairan tubuh yang bertanggung jawab untuk menjaga keseimbangan asam $(105 ; 106)$ / basa, transmisi impuls (107) saraf dan juga mengatur cairan masuk dan keluar sel $(108 ; 109)$. Ion klorida ini banyak terdapat di air laut dimana air laut mengandung $1,94 \%$ ion klorida. Berikut adalah reaksi dari sintesis ion klorida :

$$
\begin{gathered}
2 \mathrm{Cl}^{-} \rightarrow \mathrm{Cl}_{2}+2 \mathrm{e}^{-} \\
\mathrm{H}_{2} \mathrm{O}+2 \mathrm{e}^{-} \rightarrow \mathrm{H}_{2}+2 \mathrm{OH}^{-}
\end{gathered}
$$

\section{Sumber}

Di alam senyawa $\mathrm{CsCl}$ di dapati menjadi pengotor dalam mineral karnalit, silvit dan kainit.

\section{Sintesis}

Di bidang industri, $\mathrm{CsCl}$ dibuat dari mineral (110) polusit. Ekstraknya direaksikan dengan antimon triklorida $(111 ; 112)$, iodin monoklorida atau serium (IV) klorida untuk memperoleh garam yang sulit larut:

$$
\mathrm{CsCl}+\mathrm{SbCl}_{3} \rightarrow \mathrm{CsSbCl}_{4}
$$

Reaksi garam ini dengan hidrogen sulfida akan menghasilkan $\mathrm{CsCl}$ :

$\mathrm{CsSbCl}_{4}+3 \mathrm{H}_{2} \mathrm{~S} \rightarrow 2 \mathrm{CsCl}+\mathrm{Sb}_{2} \mathrm{~S}_{3}+8 \mathrm{HCl}$ (https://id.wikipedia.org/wiki/Sesium_klorida)

\section{Kegunaan Cscl}

$\mathrm{CsCl}$ digunakan secara luas dalam sentrifugasi isopiknik yang berguna untuk pemisahan berbagai jenis DNA. Cesium klorida banyak digunakan dalam sentrifugasi.Teknik yang dikenal sebagai sentrifugasi isopycnic. Pemisahan campuran berdasarkan kepadatan molekulernya dapat dilihat melalui gaya sentripetal dan difusif yang membentuk gradien densitas. Teknik ini memungkinkan pemisahan DNA dengan kepadatan berbeda (misalnya fragmen DNA dengan konten A-T atau G-C yang berbeda). Aplikasi ini membutuhkan solusi dengan kerapatan tinggi dan viskositas yang relatif rendah sehingga $\mathrm{CsCl}$ cocok karena kelarutannya yang tinggi dalam air, kepadatan tinggi karena massa Cs yang besar, serta viskositas rendah dan stabilitas tinggi.

Dalam bidang kimia analitik $\mathrm{CsCl}$ digunakan untuk mendeteksi ion anorganik melalui warna dan morfologi endapan $(113 ; 114)$. Radioisotop dari $\mathrm{CsCl}$ ini berguna dalam bidang medis seperti untuk pengobatan kanker.

\section{Parameter Transfer Ion}

a. Transport Ion

Gerakan ion dalam larutan dapat dipelajari dengan mengukur konduktivitas listrik dan larutan elektrolit. Migrasi kation menuju elektroda $(105 ; 106)$ bermuatan negatif dan anion menuju elektroda bermuatan positif, membawa muatan melalui larutan dan karenanya merupakan proses transport. 


\section{Pergerakan Ion Dalam Larutan}

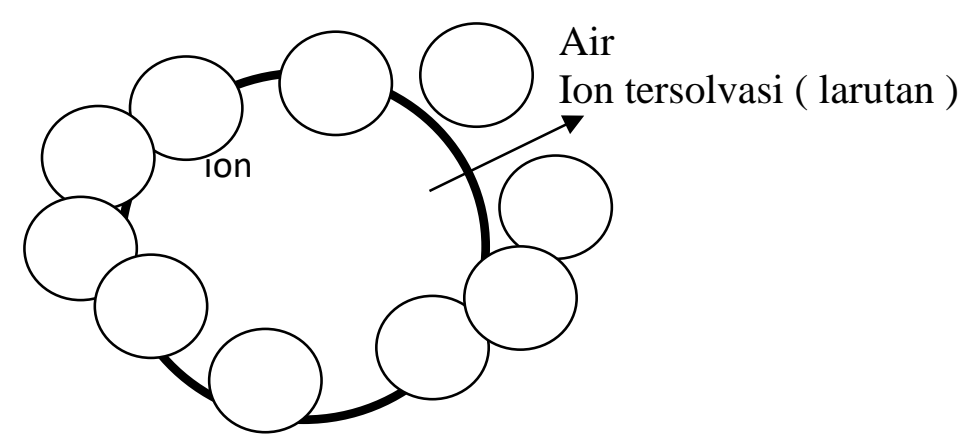

Dalam air, ion tidak mungkin berdiri sendiri namun dalam keadaan tersolvasi $(115 ; 116)$ atau terbungkus oleh molekul air. Misalnya dalam senyawa $\mathrm{CsCl}$, ion $\mathrm{Cl}$ - akan tersolvasi oleh molekul air.

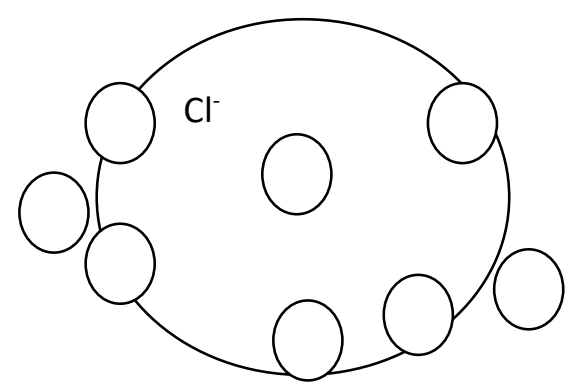

Ion tersolvasi bergerak ( aturan antivasi antara anoda dan katoda) dengan kecepatan yang berbeda sesuai dengan ukuran dan muatan . Macam macam pergerakan ion dalam larutan :

a. Migrasi $(117 ; 118)$ terjadi akibat pengaruh potensial

b. Difusi terjadi akibat pengaruh konsentrasi (119)

c. Konveksi terjadi akibat pengaruh termal (120-123)

\section{b. Mobilitas Dan Koduktivitas}

Pengukuran dasar yang digunakan untuk mempelajari gerakan ion adalah pengukuran tahanan listrik larutan. Konduktivitas larutan bergantung pada jumlah ion yang ada dan kita biasa memperkenalkan konduktivitas molar $\boldsymbol{\Lambda}_{\mathbf{m}}$, yang didefinisikan sebagai:

$$
\Lambda \mathrm{m}=\frac{K}{C}
$$

Konduktivitas (124-126) molar (127-129) elektrolit, tidak bergantung pada konsentrasi jika $k$ tepat sebanding dengan konsentrasi. Misalnya konsentrasi ion dalam larutan asam lemah bergantung pada konsentrasi asam secara rumit, dan pendua kalian konsentrasi nomial asam itu tidak mendua-kalikan jumlah tersebut.Kedua karena ion saling berantaraksi dengan kuat maka konduktivitas larutan tidak tepat sebandig dengan jumlah ion yang ada.

Konduktivitas biasanya tersedia dalam $\mathrm{S} \mathrm{Cm}^{-1}$ dan konsentrasi dalam M. Sehingga hubungan praktisnya adalah :

$$
\Lambda \mathrm{m}=\frac{100 \times \frac{K}{\left(\mathrm{Scm}^{-1}\right) \mathrm{S}} \mathrm{cm}^{2} \mathrm{~mol}^{-1}}{c / M}
$$




\begin{tabular}{cc}
\hline Ion & $\begin{array}{c}\text { Mobilitas ionik } \\
\left(10^{-8} \mathrm{~m}^{2} \mathrm{~s}^{-1} \mathrm{~V}^{-1}\right)\end{array}$ \\
\hline $\mathrm{K}+$ & 7,62 \\
$\mathrm{Na}+$ & 5,19 \\
$\mathrm{Cl}^{-}$ & 7,91 \\
$\mathrm{NO}^{-}$ & 7,40 \\
$\mathrm{~F}$ & 5,70 \\
\hline
\end{tabular}

Mobilitas ion dapat dihitung dengan pengukuran sebenarnya jarak yang ditempuh setiap ion dalam waktu tertentu dengan metode batas bergerak. makin besar mobilitas ion dalam larutan,maka makin besar pula kontribusinya pada konduktivitas (untuk muatan tertentu).

$$
\begin{gathered}
U=\frac{\boldsymbol{x}}{\boldsymbol{t}\left(\frac{\boldsymbol{d E}}{d \boldsymbol{E}}\right)} \\
\mathrm{x}=\text { jarak (m) } \\
\mathrm{t}=\text { waktu (dt) } \\
\left(\frac{d E}{d x}\right)=\text { kekuatan medan }\left(\text { volt.m }{ }^{-1}\right) \\
E=\frac{d E}{d x}=\frac{I}{A L_{s}} \\
\text { Maka }=\frac{\lambda_{m}}{z F} \\
\text { F }=\text { Faraday }(133-135) \\
t_{+}=\frac{U_{+}}{U+}+U_{-} \\
u=\frac{s}{E}
\end{gathered}
$$$$
\mathrm{F}=\text { Faraday (133-135) }
$$

Sehingga

Jika larutan elektrolit kuat pada konsentrasi molar (c) menimbulkan $v_{+}$kation dengan muatan $z_{+}$

$$
J(\text { ion })=\frac{s \Delta t A x v c N_{A}}{A \Delta t}=s v c N_{A}
$$

setiap ion membawa muatan ze sehingga fluks muatan adalah :

$$
J(\text { muatan })=z s v c e N_{A}=z s v c F
$$

Dengan $F=e N_{A}$ merupakan konstanta Faraday dan $s=u E$ maka fluksnya

$$
J(\text { mua } \tan )=z u v c F E
$$

Maka arus I : fluks muatan $\mathrm{x}$ luas 


$$
I=J A=z u v c F A E
$$

Karena medan listrik merupakan gradien $(136 ; 137)$ potensial $\Delta \phi / l$ maka :

$$
I=\frac{z u v c F A \Delta \phi}{l} \text { atau } I=\frac{\Delta \phi}{R}=\frac{L_{s} A \Delta \phi}{l}
$$

Atau

$$
L_{s}=z u v c F
$$

Untuk larutan dalam limit (138-142) konsentrasi nol :

$$
\Lambda_{m}^{0}=\left(z_{+} u_{+} v_{+}+z_{-} u_{-} v_{-}\right) F
$$

untuk elektrolit simetris $\mathrm{z}: \mathrm{z}$ (misalnya $\mathrm{CuSO}_{4}$ ) maka

$$
\Lambda_{m}^{0}=z\left(u_{+}+u_{-}\right) F
$$

Fraksi (143-147) dari arus total yang dibawa oleh ion jenis tertentu. Untuk larutan dengan 2 jenis ion, bilangan transport kation :

$$
\begin{gathered}
t_{+}=\frac{I^{+}}{I} \\
\mathrm{I}=\text { arus total } \\
I=t_{+}+t_{-}
\end{gathered}
$$

Bilangan transport pembatas $\left(\mathrm{t}^{0}\right)$ untuk limit konsentrasi nol dari larutan elektrolit. Jika $I \propto \kappa$ sehingga :

$$
t^{0}=\frac{z v u}{\sum_{i} z v u_{i}}
$$

Untuk elektrolit simetris (148-152) (bilangan muatan untuk kedua ion sama) maka persamaan diatas disederhanakan :

$$
t^{0}=\frac{u}{\sum_{i} u_{i}}
$$

Hubungan antara konduktivitas ion dengan mobilitas ion :

$$
t^{0}=\frac{v \lambda}{\sum_{i} \nu_{i} \lambda_{i}}=\frac{\nu \lambda}{\Lambda_{m}^{0}}
$$

Jadi untuk setiap jenis ion :

$$
v \lambda=t^{0} \Lambda_{m}^{0}
$$

Faktor-faktor yang mempengaruhi kecepatan ion :

a. Berat dan muatan ion, semakin ringan ion tiap satuan muatan maka akan semakin cepat ion bergerak.

b. Adanya hidrasi, semakin banyak molekul air yang mengerumuni ion maka akan semakin lambat gerakan ion. 
c. Orientasi atmosfer pelarut disekitar ion.

d. Gaya tarik antara ion, semakin besar gaya tarik maka akan semakin lambat gerakan ion.

e. Temperatur, semakin tinggi temperatur maka akan semakin cepat gerakan ion.

f. Viskositas (153-156), semakin besar viskositas maka akan semakin lambat gerakan ion.

\section{c. Penentuan Bilangan Transport $(55 ; 157-159)$}

Konsep dan pengukuran bilangan transportasi diperkenalkan oleh Johann Wilhelm Hittorf pada tahun 1853. Liquid Junction Potential dapat muncul dari ion dalam larutan yang memiliki nomor pengangkutan ion yang berbeda. Nomor angkut ion, juga disebut nomor transferensi, adalah fraksi dari total arus listrik yang dibawa dalam elektrolit oleh spesies ionik yang diberikan.

Perbedaan dalam bilangan transport ini timbul dari perbedaan dalam mobilitas listrik. Misalnya, dalam larutan natrium klorida, kurang dari setengah arus dibawa oleh ion natrium bermuatan positif (kation)(68; 160-163) dan lebih dari separuh dibawa oleh ion klorida bermuatan negatif (anion) (99; 164-166) karena ion klorida mampu bergerak. lebih cepat, hal itu di karena ion klorida memiliki mobilitas yang lebih tinggi daripada ion natrium. Jumlah dari angka transport untuk semua ion dalam larutan selalu sama dengan kesatuan.

a) Metode Hittorf

b) Metoda perbatasan bergerak

\section{Metode Hittorf}

Prinsip yang di gunakan dengan menentukan perubahan konsentrasi elektrolit disekitar elektroda yang disebabkan karena migrasi ion. Sel Hittorf ialah seperangkat alat elektrolisis $(97 ; 98 ; 167-169)$ yang terdiri atas pesawat Hittorf, sepasang elektroda, dan sumber tegangan arus searah.

Contoh :

Larutan $\mathrm{AgNO}_{3}$ ditempatkan pada sel hittorf yang dilengkapi dengan 2 buah elektroda perak yang terbagi dalam 3 bagian :

$$
\begin{array}{ll}
\text { - } & \text { ruang anoda } \\
\text { - } & \text { ruang tengah } \\
\text { - } & \text { ruang katoda }
\end{array}
$$

Jika arus listrik lewat dalam larutan, maka ion $\mathrm{Ag}^{+}$akan bermigrasi ke arah katoda dan ion $\mathrm{NO}_{3}{ }^{-}$akan bermigrasi ke arah anoda.

Pada ruang katoda :

$$
\begin{aligned}
& \text { katoda (reaksi reduksi) : } \mathrm{Ag}^{+}+\mathrm{e} \longrightarrow \mathrm{Ag} \\
& \text { Anoda (reaksi oksidasi) }: \mathrm{Ag} \longrightarrow \mathrm{Ag}^{+}+\mathrm{e}
\end{aligned}
$$

Andaikan arus yang lewat $=\mathrm{Q}$ coulomb $=\mathrm{Q} / \mathrm{F}$ faraday

sebelum arus lewat jumlah ion $\mathrm{Ag}^{+}=\mathrm{n}_{0}{ }^{\mathrm{k}}$ ekivalen

sesudah arus lewat jumlah ion $\mathrm{Ag}^{+}=\mathrm{n}^{\mathrm{k}}$ ekivalen

Jumlah ion $\mathrm{Ag}^{+}$yang bermigrasi masuk $=\mathrm{t}_{+} \mathrm{Q} / \mathrm{F}$ ekivalen (170-173)

Jumlah ion $\mathrm{NO}_{3}{ }^{-}$yang bermigrasi keluar $=\mathrm{t}$. Q/F ekivalen

Jumlah ion $\mathrm{Ag}^{+}$yang hilang karena reduksi $=\mathrm{Q} / \mathrm{F}$ ekivalen maka

$$
\begin{aligned}
\mathrm{n}^{\mathrm{k}} & =\mathrm{n}_{0}{ }^{\mathrm{k}}+\mathrm{t}_{+} \mathrm{Q} / \mathrm{F}-\mathrm{Q} / \mathrm{F} \\
& =\mathrm{n}_{0}{ }^{\mathrm{k}}+\left(\mathrm{t}_{+}-1\right) \mathrm{Q} / \mathrm{F}
\end{aligned}
$$

sehingga :

$$
t_{+}=\frac{n^{k}-n_{0}^{k}}{Q / F}+1
$$

Persamaan diatas juga bisa diturunkan dari perubahan jumlah ion $\mathrm{NO}_{3}{ }^{-}$

$$
\begin{aligned}
\mathrm{n}^{\mathrm{k}} & =\mathrm{n}_{0}{ }^{\mathrm{k}}-\mathrm{t}_{-} \mathrm{Q} / \mathrm{F} \\
& =\mathrm{n}_{0}{ }^{\mathrm{k}}+\left(1-\mathrm{t}_{+}\right) \mathrm{Q} / \mathrm{F}
\end{aligned}
$$




$$
t_{+}=\frac{n^{k}-n_{0}^{k}}{Q / F}+1
$$

Dengan menganalisa larutan didalam ruangan ini sebelum dan sesudah arus lewat dapat diketahui $n_{0}{ }^{\mathrm{k}}$ dan $\mathrm{n}^{\mathrm{k}}$, sedangkan $\mathrm{Q}$ ditentukan dari coulometer yang disusun seri dengan alat elektrolisa dalam rangkaian listrik.

Pada ruang Anoda :

$$
\begin{gathered}
n^{a}=n_{0}^{a}-t_{+} Q / F+Q / F \\
n^{a}=n_{0}^{a}-\left(t_{+}-1\right) Q / F \\
t_{+}=\frac{n_{0}^{a}-n^{a}}{Q / F}+1
\end{gathered}
$$

Analisa larutan (246-250) dari ruang tengah untuk kontrol karena jumlah ekivalen elektrolit didalam ruang ini tidak berubah karena jumlah yang masuk dan keluar sama besar. Jika hasil analisa menunjukkan adanya perubahan, maka berarti bahwa telah terjadi difusi dari ruang (251-252) anoda dan atau dari ruang katoda, maka percobaan harus di ulang dengan waktu pelewatan arus yang lebih singkat.

\section{Metode Batas Bergerak (Moving Boundary)}

Prinsip yang di gunakan ialah pipa A berisi larutan $\mathrm{HCl}$ dengan konsentrasi $\mathrm{C}$ ekivalen/liter. Anoda terbuat dari logam kadmium (174-178). Jika arus dilewatkan dalam larutan kadmium akan larut dan menghasilkan ion-ion $\mathrm{Cd}^{+}$. Baik ion $\mathrm{H}^{+}$maupun ion $\mathrm{Cd}^{2+}$ bergerak ke arah katoda, dengan ion $\mathrm{H}^{+}$ bergerak lebih cepat. Antara larutan $\mathrm{HCl}$ (179-182) dan larutan $\mathrm{CdCl}_{2}$ terdapat perbatasan yang jelas, karena ion-ion $\mathrm{Cd}^{2+}$ tidak mendahului ion-ion $\mathrm{H}^{+}$dan juga tidak ketinggalan di belakangnya karena larutan harus selalu netral (183-186).

Andaikan perbatasan berpindah dari a ke b sejauh $1 \mathrm{~cm}$ jika Q coulomb lewat. Jumlah muatan listrik yang lewat adalah $\mathrm{Q} / \mathrm{F}$ ekivalen dan dari jumlah ini $\mathrm{Q} / \mathrm{F}$. $\mathrm{t}_{+}$ekivalen dihantarkan oleh ion-ion $\mathrm{H}^{+}$. Konsentrasi ion $\mathrm{H}^{+}$dalam larutan c ekivalen/liter atau c/1000 ekivalen/cc. Volum larutan yang dilampaui oleh perbatasan $\frac{t_{+} Q}{F} \cdot \frac{1000}{c}$. Jika luas penampang pipa ialah $\mathrm{A} \mathrm{cm}^{2}$;

$$
l A=\frac{t_{+} Q}{F} \cdot \frac{1000}{c}
$$

\section{d. Kecepatan hanyut}

jika dua elektroda yang terpisah dengan jarak $\iota$ berada pada selisih potensial $\Delta \phi$,maka ion dalam larutan di antara kedua elektroda itu akan mengalami medan listrik seragam yaitu:

$$
E=\frac{\Delta \phi,}{l}
$$

Dalam medan demikian, ion yang bwermuatan ${ }^{2} z e$ mengalami gaya sebesar :

$$
\begin{gathered}
\mathrm{Ie}=z e \\
E=\frac{z e \Delta \phi}{\iota}
\end{gathered}
$$

Kation bereaksi dengan percepatan menuju elektroda negative dan anion bereaksi dengan percepatan (241-245) menuju elektroda positif. akan tetapi saat ion bergerak melalui pelarut, maka ion akan mengalami gaya gesekan sehingga memperlambat Ie yang sebanding dengan kecepatannya. Jika diasumsikan bahwa hukum Stokes (187-191) untuk bola radius a dan $s$ berlaku pada skala mikroskopis ,maka kita dapat menuliskan gaya perlambatan ini sebagai:

$$
\begin{aligned}
& \mathrm{Ie}=f s \\
& f=6 \pi \eta a
\end{aligned}
$$


Kedua gaya (237-240) itu bekerja dalam arah yang berlawanan,dan ion mencapai kecepatan akhir yaitu kecepatan hanyut, jika gaya mempercepat Ie di imbangi oleh penahan kental Ie' maka gaya neto menjadi nol (Ie = Ie' ) jika :

$$
s=\frac{z e E}{f}
$$

karena kecepatan hanyut mengatur laju transportasi ion, maka dapat mengharapkan konduktivitas akan berkurang dengan bertambahnya viskositas pelarut (192-196) akan ukuran ion.contohnya, konduktivitas molar ion logam (231-235) alkali bertambah dari $\mathrm{Li}^{+} \mathrm{ke} \mathrm{Cs}^{+}$, walaupun radius ionnya bertambah .paradoks ini terpecahkan jika kita menyadari bahwa radius $a$ dalam rumus stokes adalah radius hidrodinamik ion, yaitu radius efektifnya dalam larutan dengan memperhitungkan molekul $\mathrm{H}_{2} \mathrm{O}$ yang dibawa dalam bola hidrasinya (226-230) ion kecil menimbulkan medan listrik lebih kuat dari pada ion besar sehingga ion kecil lebih terlarut secara ekstensif dari ion besar.jadi,ion dengan radius kecil dapat mempunyai radius hidrodinamik besar,karena ion itu menyeret banyak molekul pelarut melalui larutan itu saat bermigrasi.

Proton walaupun sangat kecil mempunyai konduktivitas molar yang sangat tinggi proton bertingkah laku dengan mekanisme yang tidak bersangkutan dengan gerakan sebenarnya melalui larutan. menurut mekanisme rantai migrasi proton proton yang terlarut bukan proton tunggal,bergerak melalui larutan dengan gerakan efektif (221-225) yang bersangkutan dengan penataan ulang ikatan dalam gugusan molekul air. Konduktivitas diatur oleh laju rotasi molekul air ke dalam orientasi yang dapat menerima dan mendonorkan proton,dan laju penerobosan proton dari satu ujung ikatan hydrogen ke ujung lainnya.

Pemisalan jika potensial $\mathrm{CsCl}$ adalah 1,0 V dan jarak antara elektroda adalah $4 \mathrm{~cm}$

$\mathrm{E}=\frac{\Delta \emptyset}{t}$

$\mathrm{E}=\frac{1}{4}=0,25$, maka kecepatan hanyut $\mathrm{CsCl}$ sebesar $0,25 \mathrm{~V} / \mathrm{cm}$

\section{e. Hubungan Termodinamika}

Hukum pertama Fick tentang difusi

Andaikan fluks pertikel yang berdifusi merupakan gerakan sebagai reaksi terhadap gaya termodinamika yang timbul dari gradient konsentrasi. Partikel akan mencapai kecepatan hanyut tetap $s$ jika gaya termodinamika f sama dengan tahan kental(216-220). kecepatan hanyut ini akan sebanding dengan gaya termodinamika, dan dapat kita tuliskan $s \propto$ f. Akan tetapi, fluks partikel $J$ sebanding dengan kecepatan hanyut, dan gaya termodinamika sebanding dengan gradient konsentrasi $d c / d x$. Rantai kesebandingan itu $(J \propto s, s \propto f$, dan $£ \propto d c / d x$ menunjukkan bahwa:

Yang merupakan kandungan hukum Fick

$$
J \propto \frac{d c}{d x}
$$

\section{Hubungan Einstein}

Hukum Fick untuk fluks partikel dalam mol molekul per satuan luas per satuan waktu adalah:

$$
\mathrm{J}=-\mathrm{D} \frac{d c}{d x}
$$

Dengan D merupakan koefisien difusi dan $d c / d x$ merupakan kemiringan dari konsentrasi (211-215) molar. Adapun hubungan Fluks partikel dengan kecepatan hanyut :

$$
J=s c
$$

Hubungan ini merupakan kelanjutan dari argument yang sudah kita gunakan beberapa kali sebelumnya. Jadi, semua partikel dalam jarak $s \Delta_{\mathrm{t}} A$, dapat melewati jendela dengan luas $A$ dalam selang waktu $\Delta_{\mathrm{t}}$. Dengan demikian, jumlah mol (206-210) dapat lewat dalam selang waktu itu adalah: $s \Delta_{\mathrm{t}} \mathrm{X} c$, sehingga:

$$
S c=-\mathrm{D} \frac{d c}{d x}
$$

Jika sekarang kita menyatakan $d c / d x$ dalam $f$, menggunakan persamaan 15 , maka kita memperoleh:

$$
S=-\frac{D}{c} \frac{d c}{d x}=\frac{D}{R T} \times f
$$

Terdapat satu kasus ketika kita sudah mengetahui kecepatan hanyut dan gaya efektif yang bekerja pada partikel ialah ion dalam larutan(201-205) mempunyai kecepatan hanyut $s=\mu E$ jika ion itu mengalami gaya ez $E$, dan $z F E$ per mol, dari medan listrik dengan kuat medan E. Jadi penggantian nilai tersebut ke dalam persamaan dia atas, menghasilkan:

$$
\mu E=\frac{D}{R T} \times z F E(39)
$$


atau

$$
\mu=\frac{Z F D}{R T}
$$

Persamaan ini tertata ulang menjadi hasil yang sangat penting, yang dikenal sebagai hubungan Einstein, antara koefisien difusi dengan mobilitas ion:

$$
\mathrm{D}=\frac{\mu R T}{\mathrm{ZF}}
$$

\section{f. Viskositas}

Viskositas merupakan suatu pengukuran dari ketahanan atau kekentalan fluida (197-200) yang diubah baik dengan tekanan maupun tegangan. Pada masalah sehari-hari (dan hanya untuk fluida), viskositas adalah "Ketebalan" atau "pergesekan internal".

Rumus untuk mencari viskositas gas adalah;

$$
\mu(\mathrm{cP})=\mathrm{K}\left(\frac{t(0 C)+273}{10.000}\right)^{\mathrm{c}}
$$

viskositas kinematik didapatkan melalui perbandingan viskositas absolut dengan kerapatan :

$$
\text { viskositas kinematik }=\frac{\text { viskositas absolut }}{\text { kerapatan }}
$$

$\mathrm{CsCl}$ memiliki viskositas yang rendah sehingga dapat digunakan dalam sentrifugasi DNA. dalam dunia kimia fisika, ada beberapa prinsip penetapan viskositas yaitu :

1. Viskosimeter kapiler ( contoh : viskometer Ostwald )

Pada metode ini viskositas ditentukan dengan mengukur waktu yang dibutuhkan cairan uji untuk lewat antara dua tanda yaitu tanda awal dan akhir ketika ia mengalir karena gravitasi , melalui suatu tabung kapiler vertikal. Waktu alir dari cairan yang diuji dibandingkan dengan waktu yang dibutuhkan bagi suatu cairan yang viskositasnya sudah diketahui ( biasanya air ) untuk lewat antara dua tanda tersebut. Jika h1 dan h2 masing-masing adalah viskositas dari cairan yang tidak diketahui dan cairan standar, r1 dan r2 adalah kerapatan dari masing-masing cairan, t1 dan t2 adalah waktu alir dalam detik. Maka viskositas cairan yang tidak diketahui adalah :

$$
\begin{aligned}
& 1 \mathrm{~h}=\rho 1 . \mathrm{t} 1 \\
& 2 \mathrm{~h} \rho 2 . \mathrm{t} 2 \\
& \eta 1=\rho 1 . \mathrm{t} 1 . \mathrm{h} 2 \\
& \rho 2 . \mathrm{t} 2
\end{aligned}
$$

$\eta 2$ dan $\rho 2$ dapat diketahui dari literatur, $\rho 1$ kita diperoleh dari pengukuran kerapatan (berat jenis) dengan metode piknometer, $\mathrm{t} 1$ dan $\mathrm{t} 2$ masing-masing diketahui dengan cara mengukur waktu yang diperlukan oleh zat uji untuk mengalir melalui dua garis tanda pada tabung kapiler viskometer ostwald.

1. Viskometer bola jatuh ( viskometer Hoeppler )

Pada viskometer tipe ini, suatu bola bola besi jatuh ke bawah dalam suatu tabung gelas yang hampir vertikal, yang mengandung cairan yang diuji pada temperatur konstan. Laju jatuhnya bola yang mempunyai kerapatan dan diameter tertentu adalah kebalikan fungsi viskositas sample tersebut. Waktu bagi bola tersebut untuk jatuh antara dua tanda diukur dengan teliti dan diulangi beberapa kali. Viskositas cairan dihitung dengan rumus :

dimana $\mathrm{f}$ : gaya tahan

$$
\mathrm{f}=6 \pi \eta \mathrm{rT}
$$

$$
\begin{aligned}
& \eta \text { : viskositas } \\
& \mathrm{r}: \text { jari-jari bola } \\
& \mathrm{v}: \text { kecepatan }
\end{aligned}
$$

Pada kesetimbangan gaya ke bawah $\left(m-m^{\circ}\right) g=f$, sehingga

$$
6 \pi \eta \mathrm{rv}=\left(\mathrm{m}-\mathrm{m}_{\mathrm{o}}\right) \mathrm{g}
$$

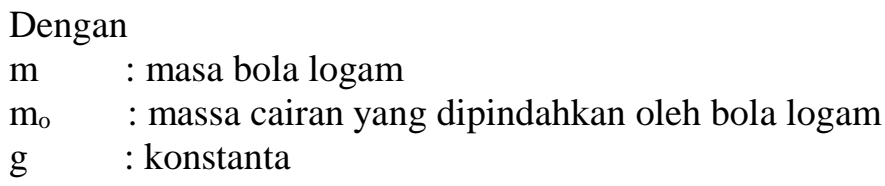




\section{Kesimpulan}

Senyawa sesium klorida merupakan senyawa ionik namun tidak sepenuhnya ionik karena elektrongativitas $\mathrm{Cs}$ sangat kecil. Konduktivitas $\mathrm{CsCl}$ termasuk rendah dan dapat larut dalam air. $\mathrm{CsCl}$ berupa padatan berwarna putih dan larut dalam air serta larut dalam etanol. Massa molar : $\quad 168.36$ g/mol Penampilan: padat putih Densitas: $3.988 \mathrm{~g} / \mathrm{cm}^{3}$ Titik didih: $1 ; 297{ }^{\circ} \mathrm{C} \quad\left(2 ; 367{ }^{\circ} \mathrm{F} ; \quad 1 ; 570 \mathrm{~K}\right)$ Kelarutan dalam air: $1910 \mathrm{~g} / \mathrm{L}\left(25^{\circ} \mathrm{C}\right)$, kecepatan hanyut $\mathrm{CsCl}$ sebesar $0,25 \mathrm{~V} / \mathrm{cm}$. CsCl memiliki kristal kubus sederhana dan dapat membentuk kisi kristal.

\section{Referensi}

1. Nian LL, Wang Y, Lu JT. 2018. On the Fano Line Shape of Single Molecule Electroluminescence Induced by a Scanning Tunneling Microscope. Nano letters

2. La Barbera L, Corbella S, Taschieri S, Galbusera F, Gianni AB, Francetti L. 2018. Augmentation of the atrophic maxillary sinus floor: graft stiffness, implant shape and length. Journal of biological regulators and homeostatic agents 32:1295-301

3. Zhao Z, Zhuo S, Fang R, Zhang L, Zhou X, et al. 2018. Dual-Programmable Shape-Morphing and Self-Healing Organohydrogels Through Orthogonal Supramolecular Heteronetworks. Advanced materials:e1804435

4. Wang C, Fadeev M, Zhang J, Vazquez-Gonzalez M, Davidson-Rozenfeld G, et al. 2018. Shapememory and self-healing functions of DNA-based carboxymethyl cellulose hydrogels driven by chemical or light triggers. Chemical science 9:7145-52

5. Guseman AJ, Perez Goncalves GM, Speer SL, Young GB, Pielak GJ. 2018. Protein shape modulates crowding effects. Proceedings of the National Academy of Sciences of the United States of America

6. Gao WY, Cardenal AD, Wang CH, Powers DC. 2018. In Operando Analysis of Diffusion in Porous Metal-Organic Framework Catalysts. Chemistry

7. Espinel-Ingroff A, Turnidge J, Alastruey-Izquierdo A, Botterel F, Canton E, et al. 2018. Method-dependent epidemiological cutoff values (ECVs) for detection of triazole resistance in Candida and Aspergillus species for the SYO colorimetric broth and Etest agar diffusion methods. Antimicrobial agents and chemotherapy

8. Wagner F, Grunder L, Hakim A, Kamber N, Horn MP, et al. 2018. Rebound After Fingolimod and a Single Daclizumab Injection in a Patient Retrospectively Diagnosed With NMO Spectrum Disorder-MRI Apparent Diffusion Coefficient Maps in Differential Diagnosis of Demyelinating CNS Disorders. Frontiers in neurology 9:782

9. Parveen S, Velmurugan G, Sinn E, Venuvanalingam P, Govindarajan S. 2018. Water-soluble Cobalt(II) \& Cobalt(III) complexes supported by new triazine Schiff base ligands: Synthesis, structure and biological evaluation. Journal of photochemistry and photobiology. B, Biology 189:152-64

10. Goncharuk SA, Artemieva LE, Tabakmakher VM, Arseniev AS, Mineev KS. 2018. CARD domain of rat RIP2 kinase: Refolding, solution structure, $\mathrm{pH}$-dependent behavior and protein-protein interactions. PloS one 13:e0206244

11. Limberg C, Lokare K, Braun-Cula B, Jorewitz M, Kelly J, et al. 2018. Structure and Reactivity of $\mathrm{Al}-\mathrm{O}(\mathrm{H})$-Al Moieties in Siloxide Frameworks - Solution and Gas phase Model Studies. Angewandte Chemie

12. Wang C, Piroozan N, Javidpour L, Sahimi M. 2018. Effect of the geometry of confining media on the stability and folding rate of alpha -helix proteins. The Journal of chemical physics 148:194305

13. Raychev D, Seifert G, Sommer JU, Guskova O. 2018. A comparative analysis of symmetric diketopyrrolopyrrole-cored small conjugated molecules with aromatic flanks: From geometry to charge transport. Journal of computational chemistry 
14. McNamara HM, Dodson S, Huang YL, Miller EW, Sandstede B, Cohen AE. 2018. GeometryDependent Arrhythmias in Electrically Excitable Tissues. Cell systems

15. Hu XY, Lou H, Hageman MJ. 2018. Preparation of lapatinib ditosylate solid dispersions using solvent rotary evaporation and hot melt extrusion for solubility and dissolution enhancement. International journal of pharmaceutics 552:154-63

16. Jouyban-Gharamaleki V, Jouyban A, Acree WE, Rahimpour E. 2018. Smart systems for determination of drug's solubility. Drug development and industrial pharmacy:1-11

17. Lidon P, Marker SC, Wilson JJ, Williams RM, Zipfel WR, Stroock AD. 2018. Enhanced Oxygen Solubility in Metastable Water under Tension. Langmuir : the ACS journal of surfaces and colloids 34:12017-24

18. Posselt M, Jaeger A, Schaper JL, Radke M, Benskin JP. 2018. Determination of polar organic micropollutants in surface and pore water by high-resolution sampling-direct injection-ultra high performance liquid chromatography-tandem mass spectrometry. Environmental science. Processes \& impacts

19. Milligan JA, Phelan JP, Polites VC, Kelly CB, Molander GA. 2018. Radical/Polar Annulation Reactions (RPARs) Enable the Modular Construction of Cyclopropanes. Organic letters

20. Hong M, Chen J, Chen EY. 2018. Polymerization of Polar Monomers Mediated by MainGroup Lewis Acid-Base Pairs. Chemical reviews

21. Matsumoto K, Kimura SI, Iwao Y, Itai S. 2017. Applicability of low-melting-point microcrystalline wax to develop temperature-sensitive formulations. International journal of pharmaceutics 532:528-36

22. Murakami TC, Mano T, Saikawa S, Horiguchi SA, Shigeta D, et al. 2018. A three-dimensional single-cell-resolution whole-brain atlas using CUBIC-X expansion microscopy and tissue clearing. Nature neuroscience 21:625-37

23. Paap MCS, Braeken J, Pedersen G, Urnes O, Karterud S, et al. 2017. A Psychometric Evaluation of the DSM-IV Criteria for Antisocial Personality Disorder: Dimensionality, Local Reliability, and Differential Item Functioning Across Gender. Assessment:1073191117745126

24. Tomaszewski KA, Klosinski M, Henry BM, Skinningsrud B, Kucharska E, et al. 2017. Large prospective validation and cultural adaptation of the Polish version of the Swiss Spinal Stenosis Questionnaire for patients with lumbar spinal stenosis. Annals of agricultural and environmental medicine : AAEM 24:676-82

25. Liu Y, Collins L, Proksch R, Kim S, Watson BR, et al. 2018. Chemical nature of ferroelastic twin domains in $\mathrm{CH} 3 \mathrm{NH} 3 \mathrm{Pbl} 3$ perovskite. Nature materials

26. Naimabadi A, Shirmardi M, Maleki H, Teymouri P, Goudarzi G, et al. 2018. On the chemical nature of precipitation in a populated Middle Eastern Region (Ahvaz, Iran) with diverse sources. Ecotoxicology and environmental safety 163:558-66

27. Kobera L, Czernek J, Abbrent S, Mackova H, Pavlovec L, et al. 2018. The Nature of Chemical Bonding in Lewis Adducts as Reflected by (27)AI NMR Quadrupolar Coupling Constant: Combined Solid-State NMR and Quantum Chemical Approach. Inorganic chemistry 57:742837

28. Lui EKJ, Hergesell D, Schafer LL. 2018. N-Silylenamines as Reactive Intermediates: Hydroamination for the Modular Synthesis of Selectively Substituted Pyridines. Organic letters

29. Vil VA, Gomes GDP, Ekimova MV, Lyssenko KA, Syroeshkin MA, et al. 2018. Five Roads That Converge at the Cyclic Peroxy-Criegee Intermediates: BF3-Catalyzed Synthesis of betaHydroperoxy-beta-peroxylactones. The Journal of organic chemistry

30. Li F, Li H, Liu X, Wang L, Lu Y, Hu X. 2018. Scalable Synthesis of Fe/N-doped Porous Carbon Nanotube Frameworks for Aqueous Zn-Air Batteries. Chemistry

31. Yoshida F, Yoshinaka H, Tanaka H, Hanashima S, Yamaguchi Y, et al. 2018. Synthesis of Core Oligosaccharides of Lipooligosaccharides from Campylobacter jejuni, a Putative Cause of Guillain-Barre Syndrome. Chemistry 
32. Guenneau S, Puvirajesinghe TM. 2013. Fick's second law transformed: one path to cloaking in mass diffusion. Journal of the Royal Society, Interface 10:20130106

33. Rauma M, Johanson G. 2009. Assessment of dermal absorption by thermogravimetric analysis: Development of a diffusion model based on Fick's second law. Journal of pharmaceutical sciences 98:4365-75

34. Missner A, Horner A, Pohl P. 2008. Cholesterol's decoupling effect on membrane partitioning and permeability revisited: is there anything beyond Fick's law of diffusion? Biochimica et biophysica acta 1778:2154-6

35. Cui ST. 2005. Molecular self-diffusion in nanoscale cylindrical pores and classical Fick's law predictions. The Journal of chemical physics 123:054706

36. Lin YP, Lu WL. 1997. [A new dynamic model of release for not-corroded drug system-revision and use of Fick's first law]. Yao xue xue bao = Acta pharmaceutica Sinica 32:869-73

37. Ackerman LKG, Martinez Alvarado JI, Doyle AG. 2018. Direct C-C Bond Formation from Alkanes Using Ni-Photoredox Catalysis. Journal of the American Chemical Society

38. Ren JT, Wang JX, Tian H, Xu JL, Hu H, et al. 2018. Ag(I)-Catalyzed [3 + 2]-Annulation of Cyclopropenones and Formamides via C-C Bond Cleavage. Organic letters

39. Zhang JS, Chen T, Zhou Y, Yin SF, Han LB. 2018. Catalytic sp(3)C-CN Bond Cleavage: NiMediated Phosphorylation of Alkylnitriles. Organic letters

40. Karanji AK, Khakinejad M, Kondalaji SG, Majuta SN, Attanayake K, Valentine SJ. 2018. Comparison of Peptide Ion Conformers Arising from Non-Helical and Helical Peptides Using Ion Mobility Spectrometry and Gas-Phase Hydrogen/Deuterium Exchange. Journal of the American Society for Mass Spectrometry

41. Mu Y, Schulz BL, Ferro V. 2018. Applications of Ion Mobility-Mass Spectrometry in Carbohydrate Chemistry and Glycobiology. Molecules 23

42. Mikek CG, West SJ, Gwin JC, Dayal N, Sintim HO, Lewis EA. 2018. Berenil Binds Tightly to Parallel and Mixed Parallel/Antiparallel G-Quadruplex Motifs with Varied Thermodynamic Signatures. ACS omega 3:11582-91

43. Raghav S, Kumar D. 2019. Comparative kinetics and thermodynamic studies of fluoride adsorption by two novel synthesized biopolymer composites. Carbohydrate polymers 203:430-40

44. Tanhaei B, Ayati A, Sillanpaa M. 2018. Magnetic xanthate modified chitosan as an emerging adsorbent for cationic azo dyes removal: Kinetic, thermodynamic and isothermal studies. International journal of biological macromolecules

45. Vieweger M, Nesbitt DJ. 2018. Synergistic SHAPE/Single-Molecule Deconvolution of RNA Conformation under Physiological Conditions. Biophysical journal 114:1762-75

46. Katoono R, Obara Y, Kusaka K, Suzuki T. 2018. Dynamic or undynamic chirality generated by helical arrangement of a shape-persistent ring and rod doubly bridged in a molecule. Chemical communications 54:735-8

47. Ishiuchi SI, Sasaki Y, Lisy JM, Fujii M. 2018. Ion-peptide interactions between alkali metal ions and a termini-protected dipeptide: modeling a portion of the selectivity filter in $\mathrm{K}(+)$ channels. Physical chemistry chemical physics : PCCP

48. Ren Y, Xie S, Svensson Grape E, Inge AK, Ramstrom O. 2018. Multistimuli-Responsive Enaminitrile Molecular Switches Displaying $\mathrm{H}(+)$-Induced Aggregate Emission, Metal IonInduced Turn-On Fluorescence, and Organogelation Properties. Journal of the American Chemical Society

49. Li M, Lu Y, An L. 2018. Ion Polarizabilities in Binary Liquid Mixtures of Water/Organic Solvents. The journal of physical chemistry. $B$

50. Pandey J, Shrivastava V, Nagarajan R. 2018. Metastable Bi2Zr2O7 with Pyrochlore-like Structure: Stabilization, Oxygen Ion Conductivity, and Catalytic Properties. Inorganic chemistry 
51. Pankratova EV, Kalyakulina AI, Krivonosov MI, Denisov SV, Taute KM, Zaburdaev VY. 2018. Chemotactic drift speed for bacterial motility pattern with two alternating turning events. PloS one 13:e0190434

52. Dirisaglik F, Bakan G, Jurado Z, Muneer S, Akbulut M, et al. 2015. High speed, high temperature electrical characterization of phase change materials: metastable phases, crystallization dynamics, and resistance drift. Nanoscale 7:16625-30

53. Zhang J, Rowe JB. 2014. Dissociable mechanisms of speed-accuracy tradeoff during visual perceptual learning are revealed by a hierarchical drift-diffusion model. Frontiers in neuroscience 8:69

54. Peng J, Cao D, He Z, Guo J, Hapala P, et al. 2018. Publisher Correction: The effect of hydration number on the interfacial transport of sodium ions. Nature

55. Peng J, Cao D, He Z, Guo J, Hapala P, et al. 2018. The effect of hydration number on the interfacial transport of sodium ions. Nature 557:701-5

56. Shan N, Liu B. 2018. Elucidating Molecular Interactions in Glycerol Adsorption at the MetalWater Interface with Density Functional Theory. Langmuir : the ACS journal of surfaces and colloids

57. Xu B, Wang W, Zhang X, Liu H, Zhang Y, et al. 2018. Electric Bias Induced Degradation in Organic-Inorganic Hybrid Perovskite Light-Emitting Diodes. Scientific reports 8:15799

58. Fujihara T, Tsuji Y. 2018. Cobalt- and rhodium-catalyzed carboxylation using carbon dioxide as the $\mathrm{C} 1$ source. Beilstein journal of organic chemistry 14:2435-60

59. Boros E, Packard AB. 2018. Radioactive Transition Metals for Imaging and Therapy. Chemical reviews

60. Crauwels M, Massa S, Martin C, Betti C, Ballet S, et al. 2018. Site-Specific Radioactive Labeling of Nanobodies. Methods in molecular biology 1827:505-40

61. Ma W, Ma H, Yang ZY, Long YT. 2018. Single Ag Nanoparticle Electro-oxidation: PotentialDependent Current Traces and Potential-Independent Electron Transfer Kinetic. The journal of physical chemistry letters 9:1429-33

62. Feliatra F, Muchlisin ZA, Teruna HY, Utamy WR, Nursyirwani N, Dahliaty A. 2018. Potential of bacteriocins produced by probiotic bacteria isolated from tiger shrimp and prawns as antibacterial to Vibrio, Pseudomonas, and Aeromonas species on fish. F1000Research 7:415

63. Kras KA, Hoffman N, Roust LR, Benjamin TR, De Filippis EA, Katsanos CS. 2018. ATP Production of Muscle Mitochondria after Acute Exercise in Lean and Obese Humans. Medicine and science in sports and exercise

64. Ang SJ, Mak AM, Wong MW. 2018. Nature of halogen bonding involving pi-systems, nitroxide radicals and carbenes: a highlight of the importance of charge transfer. Physical chemistry chemical physics : PCCP

65. de la Vega-Hernandez K, Senatore R, Miele M, Urban E, Holzer W, Pace V. 2018. Chemoselective reduction of isothiocyanates to thioformamides mediated by the Schwartz reagent. Organic \& biomolecular chemistry

66. Hu P, Berning K, Lam YW, Ng IH, Yeung CC, Lam MH. 2018. Development of a Visible Light Triggerable Traceless Staudinger Ligation Reagent. The Journal of organic chemistry

67. Matos MPV, Konstantynova KI, Mohr RM, Jackson GP. 2018. Analysis of the (13)C isotope ratios of amino acids in the larvae, pupae and adult stages of Calliphora vicina blow flies and their carrion food sources. Analytical and bioanalytical chemistry

68. Demireva $\mathrm{M}$, Armentrout PB. 2018. Samarium cation $(\mathrm{Sm}(+))$ reactions with $\mathrm{H} 2$, $\mathrm{D} 2$, and $\mathrm{HD}$ : $\mathrm{SmH}(+)$ bond energy and mechanistic insights from guided ion beam and theoretical studies. The Journal of chemical physics 149:164304

69. Kumari S, Abdul Shakoor SM, Khullar S, Mandal SK, Sakhuja R. 2018. Correction: An unprecedented tandem synthesis of fluorescent coumarin-fused pyrimidines via coppercatalyzed cross-dehydrogenative $\mathrm{C}(\mathrm{sp}(3))-\mathrm{N}$ bond coupling. Organic \& biomolecular chemistry 
70. Cozza C, Bonomi M, Pietropaolo A. 2018. A Versatile Computational Strategy To Characterize the Free-Energy Landscape of Excited States in Oligofluorenes. Journal of chemical theory and computation

71. Seetharaman S, Karr P, Coutsolelos A, Lazaro F, Sastre Santos A, D'Souza F. 2018. Sequential, Ultrafast Energy Transfer and Electron Transfer in a Fused Zinc Phthalocyanine-Free-base Porphyrin-C60 Supramolecular Triad. Chemphyschem : a European journal of chemical physics and physical chemistry

72. Xiong $E$, Zhen D, Jiang L. 2018. Homogeneous enzyme-free and entropy-driven isothermal fluorescent assay for nucleic acids based on a dual-signal output amplification strategy. Chemical communications

73. Jansen M, Freysoldt C, Merz P, Schmidt M, Mohitkar S, et al. 2018. Discovery of elusive K4O6, a compound stabilized by configurational entropy of polarons. Angewandte Chemie

74. Piaggi PM, Parrinello M. 2018. Predicting polymorphism in molecular crystals using orientational entropy. Proceedings of the National Academy of Sciences of the United States of America 115:10251-6

75. Bartel CJ, Millican SL, Deml AM, Rumptz JR, Tumas W, et al. 2018. Physical descriptor for the Gibbs energy of inorganic crystalline solids and temperature-dependent materials chemistry. Nature communications 9:4168

76. Thomas EM, Ghimire S, Kohara R, Anil AN, Yuyama KI, et al. 2018. Blinking Suppression in Highly Excited CdSe/ZnS Quantum Dots by Electron Transfer under Large Positive Gibbs (Free) Energy Change. ACS nano 12:9060-9

77. Mondal N, De A, Samanta A. 2018. Biexciton Generation and Dissociation Dynamics in Formamidinium- and Chloride-Doped Cesium Lead lodide Perovskite Nanocrystals. The journal of physical chemistry letters 9:3673-9

78. Lin F, Li F, Lai Z, Cai Z, Wang Y, et al. 2018. Mn(II)-Doped Cesium Lead Chloride Perovskite Nanocrystals: Demonstration of Oxygen Sensing Capability Based on Luminescent Dopants and Host-Dopant Energy Transfer. ACS applied materials \& interfaces 10:23335-43

79. Okiyama DCG, Soares ID, Cuevas MS, Crevelin EJ, Moraes LAB, et al. 2018. Pressurized liquid extraction of flavanols and alkaloids from cocoa bean shell using ethanol as solvent. Food research international 114:20-9

80. Tomassetti M, Angeloni R, Marchiandi S, Castrucci M, Sammartino MP, Campanella L. 2018. Direct Methanol (or Ethanol) Fuel Cell as Enzymatic or Non-Enzymatic Device, Used to Check Ethanol in Several Pharmaceutical and Forensic Samples. Sensors 18

81. Wu FM, Wang N, Pang SF, Zhang YH. 2018. Hygroscopic behavior and fractional crystallization of mixed (NH4)2SO4/glutaric acid aerosols by vacuum FTIR. Spectrochimica acta. Part A, Molecular and biomolecular spectroscopy 208:255-61

82. Liu P, Song M, Zhao T, Gunthe SS, Ham S, et al. 2018. Resolving the mechanisms of hygroscopic growth and cloud condensation nuclei activity for organic particulate matter. Nature communications 9:4076

83. Yan Y, Fu P, Jing B, Peng C, Kawamura K, et al. 2018. Corrigendum to "Hygroscopic behavior of water-soluble matter in marine aerosols over the East China Sea" [Sci. Total Environ. 578 (2017) 307-316]. The Science of the total environment 631-632:1649

84. Ta S, Das S, Ghosh M, Banerjee M, Hira SK, et al. 2018. A unique benzimidazole-naphthalene hybrid molecule for independent detection of $\mathrm{Zn}(2+)$ and N3(-) ions: Experimental and theoretical investigations. Spectrochimica acta. Part A, Molecular and biomolecular spectroscopy 209:170-85

85. Huang CB, Witomska S, Aliprandi A, Stoeckel MA, Bonini M, et al. 2018. Molecule-Graphene Hybrid Materials with Tunable Mechanoresponse: Highly Sensitive Pressure Sensors for Health Monitoring. Advanced materials:e1804600 
86. McGrath AE, Martyn AP, Whittell LR, Dawes FE, Beck JL, et al. 2018. Crystal structures and biochemical characterization of DNA sliding clamps from three Gram-negative bacterial pathogens. Journal of structural biology

87. Danilchenko SN, Kalinkevich AN, Moskalenko RA, Kuznetsov VN, Kochenko AV, et al. 2018. Structural and crystal-chemical characteristics of the apatite deposits from human aortic walls. Interventional medicine \& applied science 10:110-9

88. Zakharov BA, Michalchuk AAL, Morrison CA, Boldyreva EV. 2018. Anisotropic lattice softening near the structural phase transition in the thermosalient crystal 1,2,4,5tetrabromobenzene. Physical chemistry chemical physics : PCCP 20:8523-32

89. Li T, Qi X, Li J, Zeng H, Zou G, Lin Z. 2018. Using Multifunctional lonic Liquids in the Synthesis of Crystalline Metal Phosphites and Hybrid Framework Solids. Inorganic chemistry

90. Dias AR, Costa-Rodrigues J, Teixeira C, Gomes P, Prudencio C, Ferraz R. 2018. Ionic liquids for Topical Delivery in Cancer. Current medicinal chemistry

91. Li Y, Cui C. 2018. Cesium Carbonate-Catalyzed Oxidation of Substituted Phenylsilanes for the Efficient Synthesis of Polyhedral Oligomeric Silsesquioxanes. Inorganic chemistry

92. Duy Quang N, Eba H, Sakurai K. 2018. Versatile chemical handling to confine radioactive cesium as stable inorganic crystal. Scientific reports 8:15051

93. Puukko E, Lehto J, Lindberg A, Voutilainen M. 2018. Electromigration experiments for studying transport parameters and sorption of cesium and strontium on intact crystalline rock. Journal of contaminant hydrology 217:1-7

94. Al-Hakeim HK, Moustafa SR, Jasem KM. 2018. Serum Cesium, Rhenium, and Rubidium in Rheumatoid Arthritis Patients. Biological trace element research

95. Medvedev AA, Meshkov VV, Stolyarov AV, Heaven MC. 2018. Ab initio interatomic potentials and transport properties of alkali metal ( $\mathrm{M}=\mathrm{Rb}$ and $\mathrm{Cs}$ )-rare gas ( $\mathrm{Rg}=\mathrm{He}, \mathrm{Ne}, \mathrm{Ar}$, $\mathrm{Kr}$, and $\mathrm{Xe}$ ) media. Physical chemistry chemical physics : PCCP 20:25974-82

96. Rodriguez-Lazcano Y, Correcher V, Garcia-Guinea J. 2013. Thermo- and cathodoluminescence properties of lepidolite. Spectrochimica acta. Part A, Molecular and biomolecular spectroscopy 113:281-5

97. Zhang Q, Zhu W, Yao J, Li X, Zhou H. 2018. Electrolysis promoted reductive amination of electron-deficient aldehydes/ketones: a green route to the racemic clopidogrel. Organic \& biomolecular chemistry

98. Hou P, Wang X, Wang Z, Kang P. 2018. Gas Phase Electrolysis of Carbon Dioxide to Carbon Monoxide Using Nickel Nitride as the Carbon Enrichment Catalyst. ACS applied materials \& interfaces

99. Zheng Y, Wang X, Bai Y, Wang X, Ru C, et al. 2018. Diradical Anion of Potassium Aggregate: Reduction of Dimer Boroxide Complex. Inorganic chemistry

100. Kojima K, Watanabe HC, Doi S, Miyoshi N, Kato M, et al. 2018. Mutational analysis of the conserved carboxylates of anion channelrhodopsin-2 (ACR2) expressed in Escherichia coli and their roles in anion transport. Biophysics and physicobiology 15:179-88

101. Franck T, Aldib I, Boudjeltia KZ, Furtmuller PG, Obinger C, et al. 2018. The soluble curcumin derivative NDS27 inhibits superoxide anion production by neutrophils and acts as substrate and reversible inhibitor of myeloperoxidase. Chemico-biological interactions

102. Zhao X, Jia Y, Liu ZH. 2018. GO-graphene ink-derived hierarchical 3D-graphene architecture supported Fe3O4 nanodots as high-performance electrodes for lithium/sodium storage and supercapacitors. Journal of colloid and interface science 536:463-73

103. Tang C, Jiang X, Yin W, Liu L, Xia M, et al. 2018. Na3B7O11F2: a new sodium-rich fluorooxoborate with a unique [B14024F4] ring and a short ultraviolet absorption edge. Dalton transactions

104. Li X, Banis M, Lushington A, Yang X, Sun Q, et al. 2018. A high-energy sulfur cathode in carbonate electrolyte by eliminating polysulfides via solid-phase lithium-sulfur transformation. Nature communications 9:4509 
105. Chen H, Feng Y, Suo N, Long Y, Li X, et al. 2018. Preparation of particle electrodes from manganese slag and its degradation performance for salicylic acid in the three-dimensional electrode reactor (TDE). Chemosphere 216:281-8

106. Ratynski M, Hamankiewicz B, Krajewski M, Boczar M, Ziolkowska D, Czerwinski A. 2018. Single Step, Electrochemical Preparation of Copper-Based Positive Electrode for Lithium Primary Cells. Materials 11

107. Ezeh $\mathrm{Cl}$, Yang X, He J, Snape C, Cheng XM. 2018. Correlating ultrasonic impulse and addition of $\mathrm{ZnO}$ promoter with $\mathrm{CO} 2$ conversion and methanol selectivity of $\mathrm{CuO} / \mathrm{ZrO} 2$ catalysts. Ultrasonics sonochemistry 42:48-56

108. Wang J, Zhou J, He H, Wu D, Du X, Xu B. 2018. Cell-compatible Nanoprobes for Imaging Intracellular Phosphatase Activities. Chembiochem : a European journal of chemical biology

109. Richter-Addo GB. 2018. A structure-guided approach to ameliorate sickle cell disease. Acta crystallographica. Section D, Structural biology 74:1039-40

110. Li Q, Becker T, Zhang R, Xiao T, Sand W. 2018. Investigation on adhesion of Sulfobacillus thermosulfidooxidans via atomic force microscopy equipped with mineral probes. Colloids and surfaces. B, Biointerfaces 173:639-46

111. Kurasawa Y, Takada A, Ueda T. 1978. Color reaction of cholesterol with trichloracetic acid and antimony trichloride. On the reaction mechanism. Steroids 31:163-74

112. Hardman R, Sofowora EA. 1972. Antimony trichloride as a test reagent for steroids, especially diosgenin and yamogenin, in plant tissues. Stain technology 47:205-8

113. Ravazzolo D, Mao L, Escauriaza C, Pasten P, Montecinos M. 2018. Rusty river: Effects of tufa precipitation on sediment entrainment in the Estero Morales in the central Chilean Andes. The Science of the total environment 652:822-35

114. Ndunda EN, Madadi VO, Wandiga SO. 2018. Organochlorine pesticide residues in sediment and water from Nairobi River, Kenya: levels, distribution, and ecological risk assessment. Environmental science and pollution research international

115. Beri A, Banipal PK, Banipal TS. 2018. Effect of potassium chloride on the solvation behavior of caffeine, theophylline and theobromine: Volumetric, viscometric, calorimetry and spectroscopic approach. Food chemistry 266:110-8

116. Belenguer AM, Lampronti GI, De Mitri N, Driver M, Hunter CA, Sanders JKM. 2018. Understanding the Influence of Surface Solvation and Structure on Polymorph Stability: A Combined Mechanochemical and Theoretical Approach. Journal of the American Chemical Society

117. Vane K, Larsen T, Scholz-Bottcher BM, Kopke B, Ekau W. 2018. Ontogenetic resource utilization and migration reconstruction with delta(13)C values of essential amino acids in the Cynoscion acoupa otolith. Ecology and evolution 8:9859-69

118. Xu S, Zhao H, Zhu X, Guo D, Feng W, et al. 2018. Dissociation of $[\mathrm{HCCH}](2+)$ to $\mathrm{H} 2(+)$ and $\mathrm{C} 2(+)$ : a benchmark reaction involving $\mathrm{H}$ migration, $\mathrm{H}-\mathrm{H}$ combination, and $\mathrm{C}-\mathrm{H}$ bond cleavage. Physical chemistry chemical physics : PCCP

119. Dutt AK. 2018. Local Concentration Deviations in a Glycolytic Model of Non-Equilibrium Thermodynamics: Emergence of Bi-Stability from Thermodynamic Theories Due to Violation of Lyapunov Stability Theory. The journal of physical chemistry. B

120. Craciun AM, Mititelu Tartau L, Pinteala M, Marin L. 2018. Nitrosalicyl-imine-chitosan hydrogels based drug delivery systems for long term sustained release in local therapy. Journal of colloid and interface science 536:196-207

121. Abujabhah IS, Doyle RB, Bound SA, Bowman JP. 2018. Short-term impact of biochar amendments on eukaryotic communities in three different soils. Antonie van Leeuwenhoek

122. Stegman JR, Badin JK, Biles KA, Etienne T, Fartash-Naini S, et al. 2018. Volatile Acid-Solvent Evaporation (VASE): Molecularly Homogeneous Distribution of Acyclovir in a Bioerodable Polymer Matrix for Long-Term Treatment of Herpes Simplex Virus-1 Infections. Journal of drug delivery 2018:6161230 
123. Mei Y, Yu K, Lo JCY, Takeuchi LE, Hadjesfandiari N, et al. 2018. Polymer-Nanoparticle Interaction as a Design Principle in the Development of a Durable Ultrathin Universal Binary Antibiofilm Coating with Long-Term Activity. ACS nano

124. Cho J, Waetzig GR, Udayakantha M, Hong CY, Banerjee S. 2018. Incorporation of Hydroxyethylcellulose-Functionalized Halloysite as a Means of Decreasing the Thermal Conductivity of Oilwell Cement. Scientific reports 8:16149

125. Zhan N, Chen B, Li C, Shen PK. 2018. Molecular dynamics simulations of the thermal conductivity of graphene for application in wearable devices. Nanotechnology 30:025705

126. Zhang D, Oliynyk AO, Duarte GM, lyer AK, Ghadbeigi L, et al. 2018. Not Just Par for the Course: 73 Quaternary Germanides RE4 M2 XGe4 ( RE = La-Nd, Sm, Gd-Tm, Lu; M = Mn-Ni; X $=\mathrm{Ag}, \mathrm{Cd}$ ) and the Search for Intermetallics with Low Thermal Conductivity. Inorganic chemistry

127. Keinanen O, Partelova D, Alanen O, Antopolsky M, Sarparanta M, Airaksinen AJ. 2018. Efficient cartridge purification for producing high molar activity (18)F-glycoconjugates via oxime formation. Nuclear medicine and biology 67:27-35

128. Ret D, Steiner G, Gentilini S, Knaus S. 2019. Exact determination of the degree of substitution of high molar mass hyaluronan by controlling the conformation in solution. Carbohydrate polymers 204:124-30

129. Monnery BD, Jerca VV, Sedlacek O, Verbraeken B, Cavill R, Hoogenboom R. 2018. Defined High Molar Mass Poly(2-Oxazoline)s. Angewandte Chemie

130. Zhang Y, Chen S, Ying F, Su P, Wu W. 2018. Valence Bond Based Energy Decomposition Analysis Scheme and Its Application to Cation-pi Interactions. The journal of physical chemistry. A 122:5886-94

131. Schroder HV, Witte F, Gaedke M, Sobottka S, Suntrup L, et al. 2018. An aryl-fused redoxactive tetrathiafulvalene with enhanced mixed-valence and radical-cation dimer stabilities. Organic \& biomolecular chemistry 16:2741-7

132. Tang Z, Cheng T. 2018. Stability and aggregation of nanoscale titanium dioxide particle (nTiO2): Effect of cation valence, humic acid, and clay colloids. Chemosphere 192:51-8

133. Wang P, Lin S, Lin Z, Peeks MD, Van Voorhis T, Swager TM. 2018. A Semiconducting Conjugated Radical Polymer: Ambipolar Redox Activity and Faraday Effect. Journal of the American Chemical Society 140:10881-9

134. Arrigo R, Logsdail AJ, Torrente-Murciano L. 2018. Highlights from Faraday Discussion on Designing Nanoparticle Systems for Catalysis, London, UK, May 2018. Chemical communications 54:9385-93

135. Aldous L, Bendova M, Gonzalez-Miquel M, Swadzba-Kwasny M. 2018. Highlights from the Faraday Discussion on Ionic Liquids: From Fundamental Properties to Practical Applications, Cambridge, UK, September 2017. Chemical communications 54:5261-7

136. Miyahara T, Nakatsuji H. 2018. Photoelectron spectrum of NO2 (-) : SAC-Cl gradient study of vibrational-rotational structures. Journal of computational chemistry

137. He Z, Wang J, Hu J, Yu H, Jetten MSM, et al. 2018. Regulation of coastal methane sinks by a structured gradient of microbial methane oxidizers. Environmental pollution 244:228-37

138. Liang T, Li Z, Wang P, Zhao F, Liu J, Liu Z. 2018. Breaking Through the Signal-to-Background Limit of Upconversion Nanoprobes Using a Target-Modulated Sensitizing Switch. Journal of the American Chemical Society

139. Wang Y, Yarkony DR. 2018. Determining whether diabolical singularities limit the accuracy of molecular property based diabatic representations: The 1,2(1)A states of methylamine. The Journal of chemical physics 149:154108

140. Pereira MM, Gomes ES, Silva AV, Pinar AB, Willinger MG, et al. 2018. Biomass-mediated ZSM-5 zeolite synthesis: when self-assembly allows to cross the Si/Al lower limit. Chemical science 9:6532-9 
141. Shirts RB. 2018. Connecting the Dunham Expansion to the Dissociation Limit for Interatomic Potentials: Application to Lennard-Jones $\mathrm{m}$ - $\mathrm{n}$ Potentials. The journal of physical chemistry. A 122:8591-9

142. Zarrabi N, Yazmaciyan A, Meredith P, Kassal I, Armin A. 2018. Anomalous Exciton Quenching in Organic Semiconductors in the Low-Yield Limit. The journal of physical chemistry letters 9:6144-8

143. Pilch E, Musial W. 2018. Selected Physicochemical Properties of Lyophilized Hydrogel with Liposomal Fraction of Calcium Dobesilate. Materials 11

144. Nandeesh R, Vijayakumar S, Munnolli A, Alreddy A, Veerapur VP, et al. 2018. Bioactive phenolic fraction of Citrus maxima abate lipopolysaccharide-induced sickness behaviour and anorexia in mice: In-silico molecular docking and dynamic studies of biomarkers against NFkappaB. Biomedicine \& pharmacotherapy = Biomedecine \& pharmacotherapie 108:1535-45

145. Soni LK, Dobhal MP, Arya D, Bhagour K, Parasher P, Gupta RS. 2018. In vitro and in vivo antidiabetic activity of isolated fraction of Prosopis cineraria against streptozotocin-induced experimental diabetes: A mechanistic study. Biomedicine \& pharmacotherapy = Biomedecine \& pharmacotherapie 108:1015-21

146. Shen P, Zhang X, Lu H, Su Z, Zhou Y, et al. 2018. Effect of Fullerene Volume Fraction on TwoDimensional Crystal Constructed Supramolecular Liquid Crystals. Chemistry, an Asian journal

147. Ramirez O, Sanchez de la Campa AM, Amato F, Moreno T, Silva LF, de la Rosa JD. 2018. Physicochemical characterization and sources of the thoracic fraction of road dust in a Latin American megacity. The Science of the total environment 652:434-46

148. Victor MM, Farias RR, da Silva DL, do Carmo PHF, de Resende-Stoianoff MA, et al. 2018. Synthesis and Evaluation of Antifungal and Antitrypanosomastid Activities of Symmetrical 1,4-Disubstituted-1,2,3-Bistriazoles Obtained by CuAAC Conditions. Medicinal chemistry

149. Kotova O, Comby S, Pandurangan K, Stomeo F, O'Brien JE, et al. 2018. The effect of the linker size in C2-symmetrical chiral ligands on the self-assembly formation of luminescent triplestranded di-metallic Eu(iii) helicates in solution. Dalton transactions 47:12308-17

150. Liang R, Cotton SJ, Binder R, Hegger R, Burghardt I, Miller WH. 2018. The symmetrical quasiclassical approach to electronically nonadiabatic dynamics applied to ultrafast exciton migration processes in semiconducting polymers. The Journal of chemical physics 149:044101

151. Cao L, Luo SH, Jiang K, Hao ZF, Wang BW, et al. 2018. Disproportionate Coupling Reaction of Sodium Sulfinates Mediated by BF3.OEt2: An Approach to Symmetrical/Unsymmetrical Thiosulfonates. Organic letters 20:4754-8

152. Kwit M, Grajewski J, Skowronek P, Zgorzelak M, Gawronski J. 2018. One-step Construction of the Shape Persistent, Chiral But Symmetrical Polyimine Macrocycles. Chemical record

153. Sun W, Cui JX, Ma LL, Lu ZL, Gong B, et al. 2018. Imaging nucleus viscosity and G-quadruplex DNA in living cells using a nucleus-targeting two-photon fluorescent probe. The Analyst

154. Wylie L, Seeger ZL, Hancock AN, Izgorodina El. 2018. Increased stability of nitroxide radicals in ionic liquids: more than a viscosity effect. Physical chemistry chemical physics : PCCP

155. Hridya VM, Mukherjee A. 2018. Probing the Viscosity Dependence of Rate: Internal Friction or the Lack of Friction? The journal of physical chemistry. B 122:9081-6

156. Kailasham R, Chakrabarti R, Prakash JR. 2018. Rheological consequences of wet and dry friction in a dumbbell model with hydrodynamic interactions and internal viscosity. The Journal of chemical physics 149:094903

157. Najafi J, Shaebani MR, John T, Altegoer F, Bange G, Wagner C. 2018. Flagellar number governs bacterial spreading and transport efficiency. Science advances 4:eaar6425

158. Peng J, Cao D, He Z, Guo J, Hapala P, et al. 2018. Publisher Correction: The effect of hydration number on the interfacial transport of sodium ions. Nature 563:E18 
159. Hayashi K, Hasegawa S, Sagawa T, Tasaki S, Niwa S. 2018. Non-invasive force measurement reveals the number of active kinesins on a synaptic vesicle precursor in axonal transport regulated by ARL-8. Physical chemistry chemical physics : PCCP 20:3403-10

160. Amanchi SR, Das SK. 2018. A Versatile Polyoxovanadate in Diverse Cation Matrices: A Supramolecular Perspective. Frontiers in chemistry 6:469

161. Hong KH, Solana-Madruga E, Coduri M, Attfield JP. 2018. Complex Cation and Spin Orders in the High-Pressure Ferrite CoFe3O5. Inorganic chemistry

162. Kozaki D, Tanihata S, Yamamoto A, Nakatani N, Mori M, Tanaka K. 2019. Single injection ionexclusion/cation-exchange chromatography for simultaneous determination of organic/inorganic anions, inorganic cations, and ethanol in beer samples. Food chemistry 274:679-85

163. Nishibayashi Y, Tanabe Y, Nakajima K. 2018. Phosphine Oxidation with Water and Ferrocenium(III) Cation Induced by Visible Light Irradiation. Chemistry

164. Rabus JM, Simmons DR, Maitre P, Bythell BJ. 2018. Deprotonated carbohydrate anion fragmentation chemistry: structural evidence from tandem mass spectrometry, infra-red spectroscopy, and theory. Physical chemistry chemical physics : PCCP

165. Grommet AB, Hoffman JB, Percastegui EG, Mosquera J, Howe DJ, et al. 2018. Anion Exchange Drives Reversible Phase Transfer of Coordination Cages and Their Cargoes. Journal of the American Chemical Society

166. Gadzuk-Shea MM, Bush MF. 2018. Effects of Charge State on the Structures of Serum Albumin lons in the Gas Phase: Insights from Cation-to-Anion Proton-Transfer Reactions, Ion Mobility, and Mass Spectrometry. The journal of physical chemistry. B 122:9947-55

167. Ren L, Dong J, Chi Z, Huang H. 2018. Reduced graphene oxide-nano zero value iron (rGO$\mathrm{nZVI}$ ) micro-electrolysis accelerating $\mathrm{Cr}(\mathrm{VI})$ removal in aquifer. Journal of environmental sciences 73:96-106

168. Jud W, Kappe CO, Cantillo D. 2018. Catalyst-Free Oxytrifluoromethylation of Alkenes through Paired Electrolysis in Organic-Aqueous Media. Chemistry

169. Li A, Sun Y, Yao T, Han H. 2018. Earth-Abundant Transition-Metal Based Electrocatalysts for Water Electrolysis to Produce Renewable Hydrogen. Chemistry

170. Ji JN, Chen SL. 2018. Asymmetric abstraction of two chemically-equivalent methylene hydrogens: significant enantioselectivity of endoperoxide presented by fumitremorgin $B$ endoperoxidase. Physical chemistry chemical physics : PCCP 20:26500-5

171. Holmes JL, Abrahams BF, Ahveninen A, Boughton BA, Hudson TA, et al. 2018. Self-assembly of a Si-based cage by the formation of 24 equivalent covalent bonds. Chemical communications 54:11877-80

172. Wu Y, Zhou J, Nelson JN, Young RM, Krzyaniak MD, Wasielewski MR. 2018. Covalent Radical Pairs as Spin Qubits: Influence of Rapid Electron Motion between Two Equivalent Sites on Spin Coherence. Journal of the American Chemical Society 140:13011-21

173. Ganley JM, Christensen M, Lam YH, Peng Z, Angeles AR, Yeung CS. 2018. Metal- and AcidFree C-H Formylation of Nitrogen Heterocycles: Using Trioxane as an Aldehyde Equivalent Enabled by an Organic-Soluble Oxidant. Organic letters 20:5752-6

174. Park YR, Kim DS, Lee DH, Kang HG, Park JH, Lee SJ. 2018. Cadmium-substituted concanavalin $A$ and its trimeric complexation. Journal of microbiology and biotechnology

175. Hu S, Zhou Y, Zhou L, Huang Y, Zeng Q. 2018. Study on the adsorption behavior of cadmium, copper, and lead ions on the crosslinked polyethylenimine dithiocarbamate material.

Environmental science and pollution research international

176. Noormohamadi HR, Fat'hi MR, Ghaedi M, Ghezelbash GR. 2018. Potentiality of white-rot fungi in biosorption of nickel and cadmium: Modeling optimization and kinetics study.

Chemosphere 216:124-30 
177. Wu C, Li Y, Chen M, Luo X, Chen Y, et al. 2018. Adsorption of Cadmium on Degraded Soils Amended with Maize-Stalk-Derived Biochar. International journal of environmental research and public health 15

178. Sloup V, Jankovska I, Szakova J, Magdalek J, Sloup S, Langrova I. 2018. Effects of tapeworm infection on absorption and excretion of zinc and cadmium by experimental rats.

Environmental science and pollution research international

179. Brown TM, Gillespie BR, Smith CA, Nestler MJ, Heard GL, et al. 2018. Analysis of the Five Unimolecular Reaction Pathways of $\mathrm{CD} 2 \mathrm{ClCHFCl}$ with Emphasis on $\mathrm{CD} 2 \mathrm{Cl}(\mathrm{F}) \mathrm{C}$ : and $\mathrm{CD} 2 \mathrm{Cl}(\mathrm{Cl}) \mathrm{C}$ : Formed by $1,1-\mathrm{HCl}$ and 1,1-HF Elimination. The journal of physical chemistry. $A$ 122:8446-57

180. Doctor N, Yang Y. 2018. Separation and Analysis of Aspirin and Metformin HCl Using Green Subcritical Water Chromatography. Molecules 23

181. El-Kosasy AM, Abdel Rahman MH, Abdelaal SH. 2019. Graphene nanoplatelets in potentiometry: A nanocomposite carbon paste and PVC based membrane sensors for analysis of Vilazodone $\mathrm{HCl}$ in plasma and milk samples. Talanta 193:9-14

182. Fayomi OSI, Fayomi J, Elemike EE. 2018. Data on anti-corrosion characteristics of eco-friendly inhibitive extract on the hot corrosion degradation trend of A6063 aluminum alloy in 1.0M $\mathrm{HCl}$ solution. Data in brief 19:2468-76

183. Zhan YY, Kojima T, Nakamura T, Takahashi T, Takahashi S, et al. 2018. Induced-fit expansion and contraction of a self-assembled nanocube finely responding to neutral and anionic guests. Nature communications 9:4530

184. Zhang H, Wei Z, Jiang J, Cooks RG. 2018. Nebulization en Route to Isolate, Ionize, Dissociate and Characterize the Neutral Serine Octamer. Angewandte Chemie

185. Kotapati HK, Bates PD. 2018. A normal phase high performance liquid chromatography method for the separation of hydroxy and non-hydroxy neutral lipid classes compatible with ultraviolet and in-line liquid scintillation detection of radioisotopes. Journal of chromatography. B, Analytical technologies in the biomedical and life sciences 11021103:52-9

186. Shtepliuk I, Santangelo MF, Vagin M, Ivanov IG, Khranovskyy V, et al. 2018. Understanding Graphene Response to Neutral and Charged Lead Species: Theory and Experiment. Materials 11

187. Zhang CX, Xiang MH, Liu XJ, Wang F, Yu RQ, Jiang JH. 2019. Development of large Stokes shift, near-infrared fluorescence probe for rapid and bioorthogonal imaging of nitroxyl (HNO) in living cells. Talanta 193:152-60

188. Pearson J, Nguyen TL, Colfen H, Mulvaney P. 2018. Sedimentation of C60 and C70: Testing the Limits of Stokes' Law. The journal of physical chemistry letters 9:6345-9

189. Saarinen J, Gutter F, Lindman M, Agopov M, Fraser-Miller SJ, et al. 2018. Cell-Nanoparticle Interactions at Sub(nanometer) Resolution Analysed by Electron Microscopy and Correlative Coherent Anti-Stokes Raman Scattering. Biotechnology journal

190. Chen D, Long Z, Dang Y, Chen L. 2018. A novel fluorescent probe with red emission and a large Stokes shift for selective imaging of endogenous cysteine in living cells. The Analyst

191. Liu F, Wang Z, Zhu T, Wang W, Nie B, et al. 2019. Real-time monitoring of gammaGlutamyltranspeptidase in living cells and in vivo by near-infrared fluorescent probe with large Stokes shift. Talanta 191:126-32

192. Esrafili MD. 2018. Oxidation of SO2 over C-doped boron nitride nanosheets: The role of Cdoping, and solvent effects. Journal of molecular graphics \& modelling 86:209-18

193. Kang D, Wang Z, Chen M, Feng D, Wu G, et al. 2018. Discovery of potent HIV-1 nonnucleoside reverse transcriptase inhibitors by exploring the structure-activity relationship of solvent-exposed regions I. Chemical biology \& drug design

194. Liu Z, Shao Y, Zhu G, Wang X, Chai Y, Wang L. 2018. Gas phase reaction between chromones and solvent in an electrospray ionization source. Journal of mass spectrometry : JMS 
195. Yu HT, Chen BY, Li BY, Tseng MC, Han CC, Shyu SG. 2018. Efficient pretreatment of lignocellulosic biomass with high recovery of solid lignin and fermentable sugars using Fenton reaction in a mixed solvent. Biotechnology for biofuels 11:287

196. Lymar SV, Ertem MZ, Polyansky DE. 2018. Solvent-dependent transition from concerted electron-proton to proton transfer in photoinduced reactions between phenols and polypyridine Ru complexes with proton-accepting sites. Dalton transactions

197. Kielbasa A, Krakowska A, Rafinska K, Buszewski B. 2018. Isolation and determination of saponin hydrolysis products from Medicago sativa using supercritical fluid extraction, solid phase extraction and liqiud chromatography with evaporative light scattering detection. Journal of separation science

198. De Vecchi E, Romano CL, De Grandi R, Cappelletti L, Villa F, Drago L. 2018. Alpha defensin, leukocyte esterase, C-reactive protein, and leukocyte count in synovial fluid for preoperative diagnosis of periprosthetic infection. International journal of immunopathology and pharmacology 32:2058738418806072

199. Krotulski AJ, Mohr ALA, Fogarty MF, Logan BK. 2018. The Detection of Novel Stimulants in Oral Fluid from Users Reporting Ecstasy, Molly and MDMA Ingestion. Journal of analytical toxicology 42:544-53

200. Marinho MC, Pacheco ABF, da Costa GCV, Ortiz ND, Zajdenverg L, Sansone C. 2018. Quantitative gingival crevicular fluid proteome in type 2 diabetes mellitus and chronic periodontitis. Oral diseases

201. Dinata, A. A., Rosyadi, A. M., Hamid, S., \& Zainul, R. (2018, August 31). A Review CHEMICAL VAPOR DEPOSITION : PROCESS AND APPLICATION. https://doi.org/10.31227/osf.io/yfeau

202. Putri, D. F., Ritonga, H. M., Murdiati, V., \& Zainul, R. (2018, August 31). A REVIEW WHAT IS HYDROTHERMAL ?. https://doi.org/10.31227/osf.io/dm56c

203. Awalliyah, A., Ikhwan, H., Nugiasari, V., \& Zainul, R. (2018, August 31). A REVIEW PRINSIP DASAR MILLING DALAM SINTESIS MATERIAL.

204. Zainul, R. (2016, December 18). Design and Modification of Copper Oxide Electrodes for Improving Conversion Coefficient Indoors Lights (PV-Cell) Photocells. https://doi.org/10.31227/osf.io/pgn84

205. Zainul, R. (2016, December 18). Design and Modification of Copper Oxide Electrodes for Improving Conversion Coefficient Indoors Lights (PV-Cell) Photocells.

https://doi.org/10.31227/osf.io/pgn84

206. Zainul, R. (2016, September 24). Determination of the half-life and the quantum yield of ZnO semiconductor photocatalyst in humic acid. https://doi.org/10.31227/osf.io/e8a9x

206._Candani, D., Ulfah, M., Noviana, W., \& Zainul, R. (2018, September 1). A Review

Pemanfaatan Teknologi Sonikasi. https://doi.org/10.31227/osf.io/uxknv

207._Fatimah, P., Jumalia, R., Novianti, E. R., \& Zainul, R. (2018, August 31). A REVIEW Teknik Blended : Prinsip dan Dasar-Dasar. https://doi.org/10.31227/osf.io/tm2w4

208. Zainul, R., Oktavia, B., Dewata, I., \& efendi, j. (2017, February 4). Studi Dinamika Molekular dan Kinetika Reaksi pada Pembelahan Molekul Air untuk Produksi Gas Hidrogen. https://doi.org/10.31227/osf.io/876s3

209. Zainul, R., Alif, A., Aziz, H., Arief, S., \& s. (2015, October 22). Photoelectrosplitting Water Mechanism at Carbon Electrode Surface using Indoor lights.

https://doi.org/10.31227/osf.io/vcxq8

210. Zainul, R., Alif, A., Aziz, H., Arief, S., \& s. (2015, October 22). Photoelectrosplitting Water Mechanism at Carbon Electrode Surface using Indoor lights.

https://doi.org/10.31227/osf.io/vcxq8

211. M., Yani, S. R., \& Zainul, R. (2017, September 4). Aktivasi Tanah Napa dan Pengaruhnya Terhadap Adsorpsi lon Timbal (II)/ Pb2+. https://doi.org/10.31227/osf.io/ps523 212. Febriani, S. S., Yolanda, T., Arianti, V. A., \& Zainul, R. (2018, September 2). A Review Solid Stated : Principles and Methode. https://doi.org/10.31227/osf.io/7us4x 
213. Liza, Y. M., Yasin, R. C., Maidani, S. S., \& Zainul, R. (2018, September 29). SOL GEL : PRINCIPLE AND TECHNIQUE (A REVIEW). https://doi.org/10.31227/osf.io/2cuh8

214. Zainul, R. (2016, November 19). Effect of Temperature and Particle Motion against the ability of ZnO Semiconductor Photocatalyst in Humic Acid. https://doi.org/10.31227/osf.io/wnygb 215. chaidir, z., Zainul, R., Nurakhbari, D., \& Salim, M. (2016, September 24). Optimization of Spirulina Platensis Culture for Antioxidant Production. https://doi.org/10.17605/OSF.IO/FD6E4 216. Zainul R, Oktavia B, Dewata I, Efendi J. Thermal and Surface Evaluation on The Process of Forming a Cu2O/CuO Semiconductor Photocatalyst on a Thin Copper Plate. Proc. IOP Conference Series: Materials Science and Engineering, 2018, 335:012039: IOP Publishing 217. Zainul R, Alif A, Aziz H, Arief S, Dradjad S, Munaf E. 2015. Design of photovoltaic cell with copper oxide electrode by using indoor lights. RESEARCH JOURNAL OF PHARMACEUTICAL BIOLOGICAL AND CHEMICAL SCIENCES 6:353-61

218. Mawardi M, Deyundha D, Zainul R. Characterization of PCC Cement by Addition of Napa Soil from Subdistrict Sarilamak 50 Kota District as Alternative Additional Material for Semen Padang. Proc. IOP Conference Series: Materials Science and Engineering, 2018, 335:012034: IOP Publishing 219. Anhar A, Sumarmin R, Zainul R. 2016. Measurement of Glycemic Index of West Sumatera Local Rice Genotypes for Healthy Food Selection.

220. Zainul R, Dewata I. 2015. Determination of pH-BOD-COD and degradation in batang arau watersheds at Padang city.

221. M., Yani, S. R., \& Zainul, R. (2017, September 4). Aktivasi Tanah Napa dan Pengaruhnya Terhadap Adsorpsi lon Timbal (II)/ Pb2+. https://doi.org/10.31227/osf.io/ps523 222. P, O. M., A, L. G., S, A. Y. M., \& Zainul, R. (2018, September 1). A Review Grinding : Teknik dan Prinsip Dasar pada Pengolahan Material. https://doi.org/10.31227/osf.io/trv4q 223. H., Sanjaya, H., \& Zainul, R. (2016, August 30). Synthesis and Electrical Properties of ZnO-ITO and Al-ITO thin Film by Spin Coating Technique Through Sol Gel Process.

https://doi.org/10.31227/osf.io/unrt4

224. M., Sanjaya, H., \& Zainul, R. (2015, December 30). Characterization of napa soil and adsorption of $\mathrm{Pb}$ (II) from aqueous solutions using on column method.

https://doi.org/10.31227/osf.io/t8fh9

225. chaidir, z., Fadjria, N., A., \& Zainul, R. (2016, December 5). ISOLATION AND MOLECULAR IDENTIFICATION OF FRESHWATER MICROALGAE IN MANINJAU LAKE WEST SUMATERA. https://doi.org/10.31227/osf.io/nbcuf

226. Zainul R, Alif A, Aziz H, Arief S. 2015. DISAIN GEOMETRI REAKTOR FOTOSEL CAHAYA RUANG. Jurnal Riset Kimia 8:131

227. Zainul R, Alif A, Aziz H, Arief S, Darajat S. 2015. Modifikasi dan Karakteristik IV Sel Fotovoltaik Cu2o/Cu-Gel Na2so4 Melalui Iluminasi Lampu Neon. EKSAKTA 2:50

228. Yasthopi A. 2015. Photoelectrosplitting water for hydrogen production using illumination of indoor lights. Journal of Chemical and Pharmaceutical Research 7:246-56

229. Zainul R. 2015. Disain dan Modifikasi Kolektor dan Reflektor Cahaya pada Panel Sel Surya $\mathrm{Al} / \mathrm{Cu} 2 \mathrm{O}-\mathrm{Gel} \mathrm{Na2SO} 4$.

230. Mawardi Anwar E, Kosela S, Wibowo W, Zainul R. 2015. Study of Pb (II) biosorption from aqueous solution using immobilized Spirogyra subsalsa biomass. Journal of Chemical and Pharmaceutical Research 7:715-22

231. Iskandar, I., Horiza, H. and Fauzi, N. (2017) "EFEKTIVITAS BUBUK BIJI PEPAYA (Carica Papaya Linnaeaus) SEBAGAI LARVASIDA ALAMI TERHADAP KEMATIAN LARVA AEDES AEGYPTY TAHUN 2015", EKSAKTA: Berkala IImiah Bidang MIPA, 18(01), pp. 12-18. doi: https://doi.org/10.24036/eksakta/vol18iss01/12.

232. Ramli, R., Jonuarti, R. and Hartono, A. (2017) "ANALISIS STRUKTUR NANO DARI LAPISAN TIPIS COBALT FERRITE YANG DIPREPARASI DENGAN METODE SPUTTERING", EKSAKTA: Berkala IImiah Bidang MIPA, 18(01), pp. 46-53. doi: https://doi.org/10.24036/eksakta/vol18-iss01/16.

233. Sanjaya, H. (2017) "DEGRADASI METHYLENE BLUE MENGGUNAKAN KATALIS ZnO-PEG DENGAN METODE FOTOSONOLISIS", EKSAKTA: Berkala IImiah Bidang MIPA, 18(02), pp. 21-29. doi: https://doi.org/10.24036/eksakta/vol18-iss02/45. 
234. Ningsih, S. K. (2017) "SINTESIS DAN KARAKTERISASI NANOPARTIKEL ZnO DOPED Cu2+ MELALUI METODA SOL-GEL", EKSAKTA: Berkala IImiah Bidang MIPA, 18(02), pp. 39-51. doi:

https://doi.org/10.24036/eksakta/vol18-iss02/51.

235. Saiya, A. (2017) "ANALISIS RESIDU KLORPIRIFOS DALAM SAYURAN KUBIS DENGAN METODE HPLC DI BEBERAPA PASAR TRADISIONAL DI SULAWESI UTARA", EKSAKTA: Berkala Ilmiah Bidang MIPA, 18(02), pp. 7785. doi: https://doi.org/10.24036/eksakta/vol18-iss02/57.

236. Iskandar, I., Horiza, H. and Fauzi, N. (2017) "EFEKTIVITAS BUBUK BIJI PEPAYA (Carica Papaya Linnaeaus) SEBAGAI LARVASIDA ALAMI TERHADAP KEMATIAN LARVA AEDES AEGYPTY TAHUN

2015", EKSAKTA: Berkala Ilmiah Bidang MIPA, 18(01), pp. 12-18. doi: https://doi.org/10.24036/eksakta/vol18iss01/12.

237. Ramli, R., Jonuarti, R. and Hartono, A. (2017) "ANALISIS STRUKTUR NANO DARI LAPISAN TIPIS COBALT FERRITE YANG DIPREPARASI DENGAN METODE SPUTTERING", EKSAKTA: Berkala IImiah Bidang MIPA, 18(01), pp. 46-53. doi: https://doi.org/10.24036/eksakta/vol18-iss01/16.

238. Sanjaya, H. (2017) "DEGRADASI METHYLENE BLUE MENGGUNAKAN KATALIS ZnO-PEG DENGAN METODE FOTOSONOLISIS", EKSAKTA: Berkala IImiah Bidang MIPA, 18(02), pp. 21-29. doi: https://doi.org/10.24036/eksakta/vol18-iss02/45.

239. Ningsih, S. K. (2017) "SINTESIS DAN KARAKTERISASI NANOPARTIKEL ZnO DOPED Cu2+ MELALUI METODA SOL-GEL", EKSAKTA: Berkala IImiah Bidang MIPA, 18(02), pp. 39-51. doi: https://doi.org/10.24036/eksakta/vol18-iss02/51.

240. Saiya, A. (2017) "ANALISIS RESIDU KLORPIRIFOS DALAM SAYURAN KUBIS DENGAN METODE HPLC DI BEBERAPA PASAR TRADISIONAL DI SULAWESI UTARA", EKSAKTA: Berkala Ilmiah Bidang MIPA, 18(02), pp. 7785. doi: https://doi.org/10.24036/eksakta/vol18-iss02/57.

241. Syafei, N. (2017) "ANALISA FENOMENA KOROSI PELAT PIPA BAJA KARBON API 5L-X65 DALAM LARUTAN 250 ML ASAM ASETAT DAN 4750 ML AQUADES PADA KONDISI GAS CO2 DAN H2S JENUH PADA SUHU RUANG", EKSAKTA: Berkala IImiah Bidang MIPA, 18(02), pp. 113-120. doi: https://doi.org/10.24036/eksakta/vol18-iss02/63.

242. Tutuarima, T. (2017) "SIFAT FISIK DAN KIMIA MARMALADE JERUK KALAMANSI (Citrus microcarpa) : KAJIAN KONSENTRASI PEKTIN DAN SUKROSA Physical and Chemical Properties of Marmalade Citrus of Calamondin (Citrus microcarpa) : Study of Pectin and Sucrose Concentrations", EKSAKTA: Berkala IImiah Bidang MIPA, 18(02), pp. 164-172. doi: https://doi.org/10.24036/eksakta/vol18-iss02/73.

243. Ruswandi, R. (2018) "Determination of Fructose Content resulted by Inulin Hydrolysis with DNS as Oxidizer", EKSAKTA: Berkala IImiah Bidang MIPA, 19(1), pp. 14-23. doi: https://doi.org/10.24036/eksakta/vol19iss1/102.

244. Sanjaya, H. (2018) "DEGRADASI METIL VIOLET MENGGUNAKAN KATALIS ZnO-TiO2 SECARA FOTOSONOLISIS", EKSAKTA: Berkala IImiah Bidang MIPA, 19(1), pp. 91-99. doi: https://doi.org/10.24036/eksakta/vol19-iss1/131.

245. Hidayani, T. (2018) "GRAFTING POLIPROPILENA DENGAN MALEAT ANHIDRIDA SEBAGAI PENGIKAT SILANG DENGAN INISIATOR BENZOIL PEROKSIDA", EKSAKTA: Berkala IImiah Bidang MIPA, 19(1), pp. 56-62. doi: https://doi.org/10.24036/eksakta/vol19-iss1/127.

246. Prabowo, H. (2018) "PENYELIDIKAN KELAYAKAN KIMIA DAN PENYEBARAN CADANGAN PASIR BESI DAERAH TIKU KABUPATEN AGAM UNTUK BAHAN BAKU SEMEN PADA PT. SEMEN PADANG", EKSAKTA: Berkala IImiah Bidang MIPA, 19(1), pp. 39-42. doi: https://doi.org/10.24036/eksakta/vol19-iss1/121.

247. Syafei, N. (2018) "Riset Material ANALISA FENOMENA KOROSI PELAT PIPA BAJA KARBON API 5L-X65 DALAM LARUTAN 7900 ML AIR LAUT DAN 100 ML AMONIAK PADA KONDISI GAS CO2 DAN H2S JENUH PADA SUHU RUANG.", EKSAKTA: Berkala IImiah Bidang MIPA, 19(1), pp. 7-13. doi: https://doi.org/10.24036/eksakta/vol19-iss1/83.

248. Parbuntari, H., Prestica, Y., Gunawan, R., Nurman, M. and Adella, F. (2018) "Preliminary Phytochemical Screening (Qualitative Analysis) of Cacao Leaves (Theobroma cacao L.)", EKSAKTA: Berkala IImiah Bidang MIPA, 19(2), pp. 40-45. doi: https://doi.org/10.24036/eksakta/vol19-iss2/142. 
249. Dinata, M. and Soehardi, F. (2018) "Factor Analysis of Physics Chemistry Waters that Affects Damage Safety Cliff on the Outskirts of River Siak", EKSAKTA: Berkala IImiah Bidang MIPA, 19(2), pp. 46-49. doi: https://doi.org/10.24036/eksakta/vol19-iss2/143.

250. Sofyanita, S. and Octaria, Z. (2018) "Fenthion Compound Degradation in the Pesticide Bayleton 500 ec in Sonolysis, Ozonolysis and Sonozolysis with Addition of TiO2-anatase", EKSAKTA: Berkala IImiah Bidang MIPA, 19(2), pp. 70-79. doi: https://doi.org/10.24036/eksakta/vol19-iss2/153.

251. Harahap, F. and Lubis, L. (2018) "Analysis of Heavy Metals Distribution in the River Town of Hamasaki's Rod Padangsidimpuan", EKSAKTA: Berkala IImiah Bidang MIPA, 19(2), pp. 50-56. doi: https://doi.org/10.24036/eksakta/vol19-iss2/149.

252. Syafei, N., Hidayat, D., Emilliano, E. and Men, L. (2018) "Analysis Cracking Corrosion on Carbon Steel Pipes API 5L-X65 In Solution $7700 \mathrm{ml}$ Aquades, $250 \mathrm{ml}$ Acetic Acid and $50 \mathrm{ml}$ Ammonia with Gas CO2 and H2S in Saturation Condition", EKSAKTA: Berkala I/miah Bidang MIPA, 19(2), pp. 21-31. doi: https://doi.org/10.24036/eksakta/vol19-iss2/138. 